\title{
Modelling, assessment and Sankey diagrams of integrated electricity-heat-gas networks in multi-vector district energy systems
}

Xuezhi Liu and Pierluigi Mancarella

xuezhi.liu@manchester.ac.uk; p.mancarella@manchester.ac.uk

Abstract

The widespread use of decentralised multi-energy supply solutions such as gas-fired Combined Heat and Power (CHP), heat pumps, gas boilers, and so forth is more and more increasing the linkages between electricity, heat and gas distribution networks. However, there is currently no model able to model the three networks in an integrated manner and with a suitable level of detail for operational purposes. A multi-temporal simulation model, which has been implemented in a relevant MATLAB-Excel VBA tool, is presented in this paper to carry out integrated analysis of electricity, heat and gas distribution networks, with specific applications to multi-vector district energy systems. The network linkages have been modelled through a multi-vector efficiency matrix specifically developed to map the transformation of final demands into network energy flows while taking into account the inter-network locations of the individual supply technologies. The relevant coupled electrical, heat and gas flow equations have been solved simultaneously using a Newton-Raphson approach. A real case study of a district multi-energy system in the Campus of the University of Manchester illustrates the quantitative use of the model in different scenarios for technical, economic and environmental studies. Sankey diagrams of the energy flows across the networks are also presented to give a visual picture of the multi-energy interactions and losses in the district in different scenarios. The model can be flexibly adapted to generic network topologies and multi-energy supply technologies, and can thus be used for practical operational implementations as well as to inform planning of low carbon multi-vector energy systems.

23 Index Terms - multi-energy systems; energy system integration; district energy systems; district heating; gas network; load flow solution.

\section{Nomenclature}

\section{Variables}

$V \quad$ Voltage $(\mathrm{V})$

$\theta \quad$ Voltage angle ( $\mathrm{rad})$

$P \quad$ Electrical real power $\left(\mathrm{MW}_{\mathrm{e}}\right)$

$Q \quad$ Electrical reactive power (MVar)

$S \quad$ Electrical complex power (MVA)

$\Phi \quad$ Heat power $\left(\mathrm{MW}_{\text {th }}\right)$

$\dot{m} \quad$ Mass flow rate within each pipe $(\mathrm{kg} / \mathrm{s})$

$T_{s} \quad$ Supply temperature at a node in the supply network $\left({ }^{\circ} \mathrm{C}\right)$

$T_{o} \quad$ Return temperature at the outlet of a node before mixing in the return network $\left({ }^{\circ} \mathrm{C}\right)$

$T_{r} \quad$ Return temperature at a node after mixing in the return network $\left({ }^{\circ} \mathrm{C}\right)$

$T_{a} \quad$ Ambient temperature $\left({ }^{\circ} \mathrm{C}\right)$

$v \quad$ Flow velocity $(\mathrm{m} / \mathrm{s})$ 


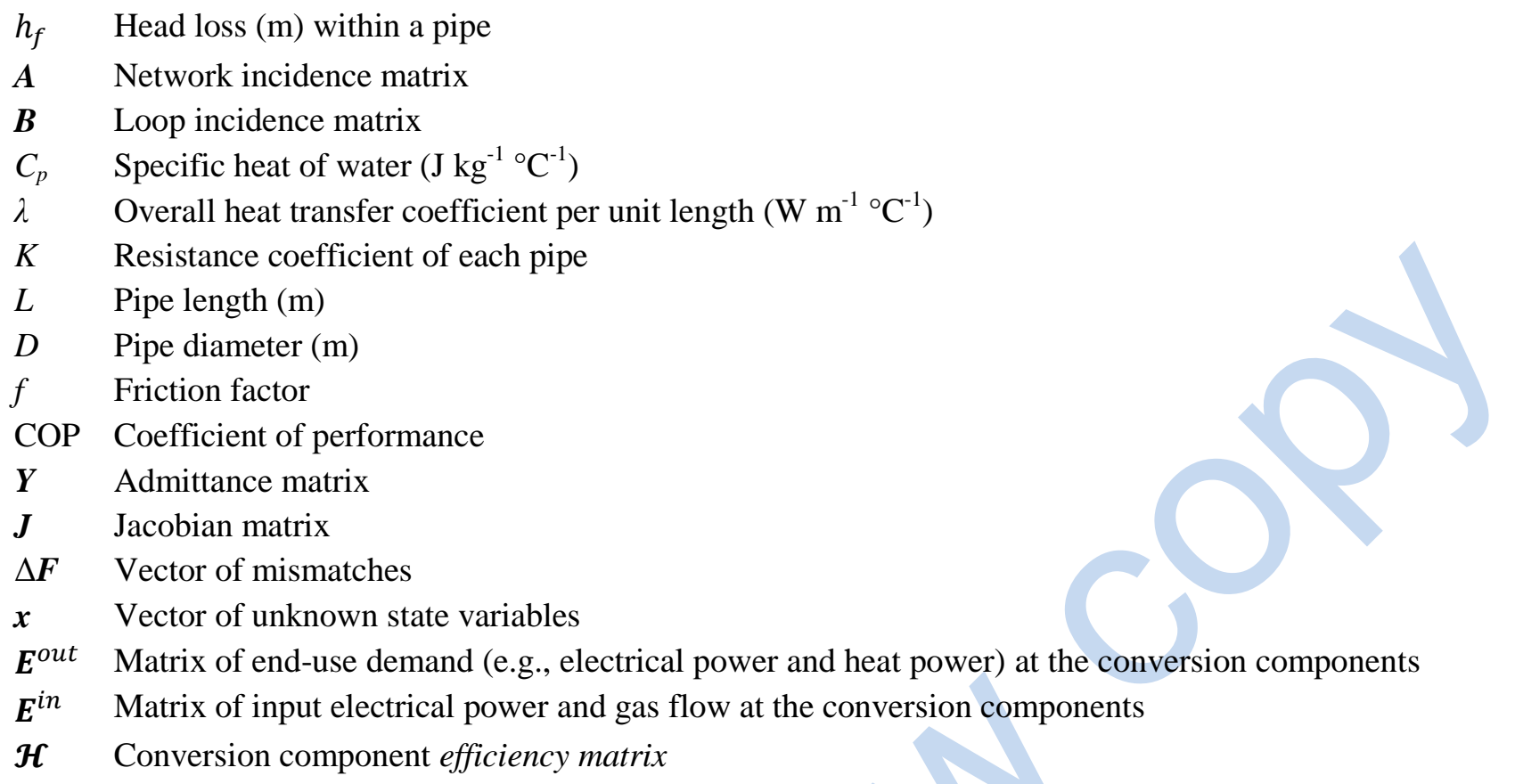

\section{Subscripts and Superscripts}

$\begin{array}{ll}e & \text { electrical network } \\ h & \text { heat network } \\ g & \text { gas network } \\ q & \text { nodal variables } \\ s p & \text { specified }\end{array}$

\section{1. Introduction}

29 As the penetration of multi-energy low carbon technologies (such as Combined Heat and Power (CHP), micro30 CHP, heat pumps, and so forth) increases, the interactions between electricity, heat and gas networks become 31 tighter, and modelling of Multi-vector (or multi-carrier) Energy Systems (MES) [1] as an integrated whole 32 becomes more important [1-4]. This applies particularly at the district level, where the vision of having smarter 33 cities is calling for new models that are capable to assess in an integrated fashion the downsides and upsides of 34 the tighter interactions of multiple energy vectors. However, the majority of tools available address individual 35 energy networks and are not capable to model multi-vector networks with the required level of detail for 36 operational integrated analysis of district energy systems ${ }^{1}$.

37 The importance of multi-vector network interaction is growing in research and practical applications, as 38 demonstrated by recent work on multi-energy systems and distributed multi-generation [1, 4-6], energy hubs [3], 39 intelligent energy systems [7], community energy [5], smart energy systems and EnergyPlan [8-10], and 40 integrated energy systems [11]. Various methods have been developed to investigate combined electricity and

\footnotetext{
${ }^{1}$ In this work, "district energy systems" refer to multi-energy systems at the district level, and including in particular electrical, thermal and gas network infrastructure, whose analysis is the focus of this work, as expanded upon later.
} 
natural gas networks [3, 12-15], mostly with focus on transmission systems whereby gas turbine generators provide the linkage between gas and electricity networks. Likewise, there have been a few studies that have investigated combined electricity and heat networks $[16,17]$. A review of different computer tools that can be used to analyse the integration of renewable energy into multi-energy systems was conducted in [18]. However, in all the models and tools $[3,12-18]$ detailed network analysis was not conducted by taking into account detailed multi-energy network topologies and locations of generators and energy conversion technologies to calculate network operational variables and losses. The electrical, thermal and gas power flows were calculated independently and linked through generating units. Operational analysis of multi-energy systems has for instance been performed in $[8,9]$, but with no consideration for network modelling. Integrated electricity and heat analysis has been performed in [2,19], however with limited applications in terms of conversion components. There is no model that has insofar integrated electricity, heat and gas networks, with the level of detail needed for operational assessment in multi-vector district energy systems and with generic conversion technologies coupling the three networks. In particular, this is key to be able to model new technologies mixes such as based on CHP and heat pumps $[4,20,21]$, as diversifying the heat delivery options within a district or city with integrated electricity, heat and gas system modelling may facilitate the development of a low carbon energy system [22, 23]. In this respect, chains of conversion can be visually mapped in Sankey diagram form [24], with the possibility to identify areas with largest energy flows and largest energy efficiency potential. For example, a framework for designing Sankey diagrams for national level analysis is presented in [25]. However, there are no studies visually mapping energy flows following integrated network analysis at a district level.

On the above premises, in this paper a model for integrated analysis of electricity, heat and gas networks is presented, able to model the multi-vector interactions across networks as a whole and to incorporate general energy conversion components so as to assess their impact on the operation (and then design) of the MES district. The model has been coded into a relevant MATLAB tool with Excel-VBA interface. The network linkages through various conversion components (including gas-fired power generators, CHP, heat pumps, gas boilers, electric boilers, and so forth, located at different levels of the networks) are modelled in a flexible way through a specifically developed multi-network efficiency matrix that accounts for conversion efficiencies of individual supply technologies, maps the transformation of end-use demand into the energy flows in the different networks, and adopts a specific node numbering topological description to consider the inter-network locations of the different conversion components. The relevant coupled electrical (active and reactive power), heat (thermal and hydraulic) and gas (hydraulic) equations are solved simultaneously by adopting a Newton-Raphson technique that allows fast development of multi-vector analysis, following the work in $[2,19]$ for electricity and heat 72 networks.

A real case study of a multi-vector district energy system at the University of Manchester is analysed to illustrate the capability of the tool to assess in a quantitative manner the implication of the multi-vector interactions on different energy networks. More specifically, via time series data analysis the model is used to investigate the impact of a variety of supply technologies on the three networks in a number of scenarios, with relevant energy efficiency, $\mathrm{CO}_{2}$ emission and operational cost studies. Detailed Sankey diagrams of multi-network energy flows for each scenario are also presented, to highlight in a visual way changes in energy flows and losses across networks for different sets of conversion components. 


\section{Multi-energy network modelling tool}

\subsection{General tool overview}

A schematic of energy flows showing possible interactions between electrical, heat and gas networks at the district level is shown in Figure $1^{2}$.

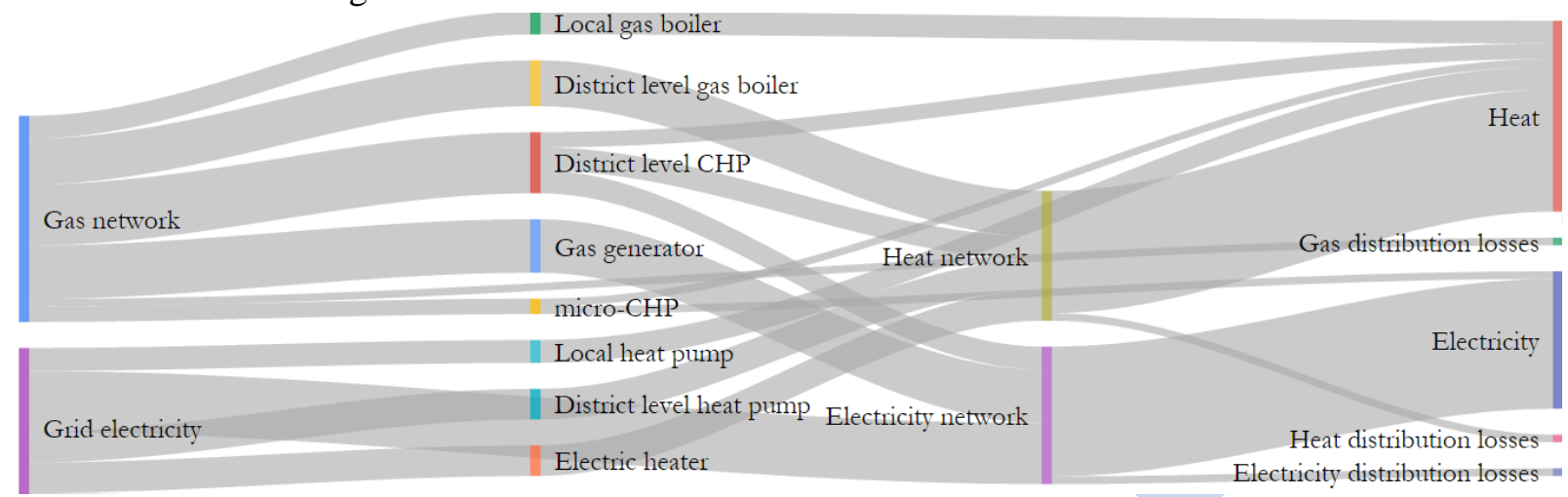

Figure 1: Schematic of energy flows of electrical, heat and gas networks at the district level

86

87

88

The electricity and heat networks are linked through various conversion components (e.g., CHP, heat pumps, and electric boilers). These components allow flows of energy between the two networks: CHP units generate electricity and heat simultaneously; heat pumps consume electricity to leverage heat from the surroundings and bring it to higher temperatures for indoor use, while electric boilers convert electricity to heat via Joule effect. The gas network then interacts with the electrical network via gas generators or CHP and with the heat network via boiler or CHP.

The tight interactions between electricity, heat and gas networks call for an integrated analysis to model the multi-energy networks as an integrated whole. The model should be capable to incorporate any kind of energy conversion components and assess their impact on the technical operation and flows and losses of the three networks. This would eventually also allow energy efficiency, carbon emission and energy cost calculations as well as Sankey diagram representation of the multi-network energy flows under different conditions.

The combined analysis of electricity-heat-gas networks starts from the energy flow equations of each network. The AC electrical power flow model for electrical networks is well established (see for instance [26, 27]). The integrated hydraulic-thermal equations for heat networks is described in $[2,19]$. The gas flow equations are in the same form as hydraulic ones in heat networks, as detailed later. The combined equations of all three networks are solved in this paper simultaneously by a Newton-Raphson approach, with a slack node for each network.

\subsection{Input and output data}

A template for handling input and output data needed for the integrated analysis has been developed in an Excel spreadsheet. More specifically, there are six Tabs for input data in the spreadsheet:

- $\quad$ electricity network parameters;

- $\quad$ heat network parameters;

\footnotetext{
${ }^{2}$ For simple illustration purpose, the conversion losses are not shown in this diagram. The detailed amount of energy flows is shown in Section 4.
} 
- $\quad$ gas network parameters;

- $\quad$ conversion components parameters;

- $\quad$ electrical load time series at specific locations;

- heat load time series at specific locations.

111 The multi-energy load profiles at different consumption nodes are given at a half-hourly time resolution in the case study in Section 3, but the model is flexible to handle different time steps and analysis time windows.

The fields of electricity network parameter data are:

- resistance (in per unit, p.u.) and reactance (p.u.) for each line or transformer;

- electrical active power (MW) and reactive power (MVar) at different nodes;

- $\quad$ voltage magnitude (p.u.) at each source.

The fields of heat network parameter data are:

- pipe length (m), pipe diameter $(\mathrm{m})$, roughness $(\mathrm{m})$, heat transfer coefficient $\left.\left(\mathrm{W} \mathrm{m}^{-1}{ }^{\circ} \mathrm{C}^{-1}\right)\right)$ for each branch;

- heat power (MW) for each node;

- supply temperature $\left({ }^{\circ} \mathrm{C}\right)$ at each source and return temperature $\left({ }^{\circ} \mathrm{C}\right)$ at each load.

The fields of gas network parameter data are:

- $\quad$ pipe length $(\mathrm{m})$ and pipe diameter $(\mathrm{m})$ for each branch;

- heat load from gas (MW).

The fields of conversion component parameter data are:

- efficiencies (electrical efficiency and heat-to-power ratio for CHP; coefficient of performance (COP) for heat pumps, thermal efficiency for electric and gas boilers).

Tabs for output data in the spreadsheet include:

- $\quad$ voltages, active and reactive power, and losses in the electrical network;

- mass flow rates, supply and return temperatures, heat power, and losses in the heat network;

- gas flow rates, nodal pressures, and losses in the gas network;

- $\mathrm{CO}_{2}$ emissions;

- operational costs.

Furthermore, detailed Sankey diagrams of multi-network energy flows are presented, visually mapping the three networks' energy flows from supply to demand through energy conversion technologies.

\subsection{Multi-energy network topology model}

From the input data, three network incidence matrices that relate the nodes to the branches and one multi-energy conversion efficiency matrix are generated automatically.

Electricity, heat and gas networks are described using their respective incidence matrix. Each element of the network incidence matrix describes:

- $\quad+1$, if the flow in a branch comes into a node;

- $\quad-1$, if the flow in a branch leaves a node; 
- $\quad 0$, if no connection from a branch to a node. A specific numbering approach has been used to model the topology of the different networks and their linkages through conversion components. Each conversion component has its own "local" node numbering at each network. To link the different local node numberings of each conversion component in each network, an additional numbering, which is referred to as "global" node numbering, is introduced as shown in Figure 2. Hence, two numberings are used for each conversion component node: the local node numbering represents the node numbering in each network, while the global node numbering represents a unique node numbering in whole electrical, heat and gas networks. In Figure 2, a conversion component with global numbering node 2 is numbered node 5 in the electrical network, node 3 in the heat network and node 4 in the gas network. Although the local node numbering of a conversion component in each network is different, the unique global node numbering links its different local node numberings in each network. Through using global node numbering, the integrated model reduces dimensionality especially when conversion components are of high density. This is because equations of conversion components models are substituted into electrical, heat and gas power flow equations, and then the total number of equations reduces.

In the multi-energy efficiency matrix, there are as many columns as transformations, for example, three columns in the case of gas to electricity, gas to heat, and electricity to heat supply. There are as many rows as conversion components in the district. Each element of the matrix is the relevant conversion efficiency from one energy vector to another energy vector. An example of an efficiency matrix $\mathcal{H}$ of conversion components is shown in Table 1 . The dimension of $\mathcal{H}$ is $N_{\text {con }} \times 3$, where $N_{\text {con }}$ is the number of total conversion components. Depending on the specific context and application, a number of other conversion components, such as electrolysers, biogas plants, thermal gasification, electric chillers, absorption chillers, etc., can also be readily modelled within the

Table 1: An example of an efficiency matrix of conversion components

\begin{tabular}{c|l|c|c|c}
\hline Global node numbering & \multicolumn{1}{|c|}{ Type } & Gas to electricity & Gas to heat & Electricity to heat \\
\hline 1 & CHP (large scale) & $H_{g} \eta_{g e}^{1}$ & $H_{g} \eta_{g h}^{1}$ & \\
\hline 2 & CHP (building 1) & $H_{g} \eta_{g e}^{2}$ & $H_{g} \eta_{g h}^{2}$ & \\
\hline 3 & Gas generator (building 2) & $H_{g} \eta_{g e}^{3}$ & & \\
\hline 4 & Heat pump (building 3) & & & $\eta_{e h}^{4}$ \\
\hline
\end{tabular}




\begin{tabular}{c|l|c|c|c}
\hline 5 & Electric heater (building 4) & & & $\eta_{e h}^{5}$ \\
\hline 6 & Gas boiler (building 5) & & $H_{g} \eta_{g h}^{6}$ & \\
\hline 7 & CHP (building 6) & $H_{g} \eta_{g e}^{7}$ & $H_{g} \eta_{g h}^{7}$ & \\
\hline 8 & CHP (building 7) & $H_{g} \eta_{g e}^{8}$ & $H_{g} \eta_{g h}^{8}$ & \\
\hline 9 & Heat pump (building 8) & & & $\eta_{e h}^{9}$ \\
\hline 10 & Heat pump (building 9) & & & $\eta_{e h}^{10}$ \\
\hline 11 & Gas boiler (building 10) & & $H_{g} \eta_{g h}^{11}$ & \\
\hline
\end{tabular}

In Table $1, H_{g}$ is the heating value of natural gas, $H_{g}=39 \mathrm{MJ} / \mathrm{m}^{3}$. The unit of gas flow is $\mathrm{m}^{3} / \mathrm{h}$ and the unit of electrical and heat power is MW. Hence, to make the units consistent, the efficiency of gas is multiplied by $H_{g}$.

\subsection{Electrical network model}

171 Given a power system described by an admittance matrix, and given a subset of voltage magnitudes, voltage 172 angles and real and reactive power injections, the electrical power flow determines the other voltage magnitudes and angles, and real and reactive power injections. Specifically, the input variables are: voltage magnitudes at PV busbars (busbars with known active power and voltage magnitude); active power at non-slack busbars; and reactive power at PQ busbars (busbars with known active power and reactive power). The unknown variables are: voltage angles $\theta$ at non-slack busbars; voltage magnitudes $|\boldsymbol{V}|$ at $\mathrm{PQ}$ busbars.

177 The voltage $V$ at busbar $i$ is given by

$$
V_{i}=\left|V_{i}\right| \angle \theta_{i}=\left|V_{i}\right| e^{j \theta_{i}}=\left|V_{i}\right|\left(\cos \theta_{i}+j \sin \theta_{i}\right)
$$

178 where $|V|$ is the voltage magnitude (p.u.). $\theta$ is the voltage angle (rad). $j$ is the imaginary unit.

179 The current injected into the network at busbar $i$ is given by

$$
I_{i}=\sum_{n=1}^{N_{e}} Y_{i n} V_{n}
$$

180

where $N_{e}$ is the number of busbars in the electricity network; $\boldsymbol{Y}$ is the admittance matrix that relates current injection at a busbar to the busbar voltage [26,27]. Current injections may be either positive (into the busbar) or negative (out of the busbar).

The electrical network incidence matrix $\boldsymbol{A}_{\boldsymbol{e}}$ is used to form the diagonal of the admittance matrix $\boldsymbol{Y}$ [26-28]. The diagonal of the electrical admittance matrix is expressed as the product of the electrical network incidence matrix $\boldsymbol{A}_{\boldsymbol{e}}$ and the vector of line admittance. Each element of the off-diagonal of the admittance matrix $Y_{\text {in }}$ is the negative of the corresponding line admittance input from busbar $i$ to busbar $n$.

Thus, the calculated complex power injected at busbar $i$ is

$$
S_{i}=P_{i}+j Q_{i}=V_{i} I_{i}{ }^{*}=V_{i} \sum_{n=1}^{N_{e}}\left(Y_{i n} V_{n}\right)^{*}
$$

where $S$ is complex power, $P$ is active power, $Q$ is reactive power.

Equation (3) constitutes the polar form of the electrical power flow equations. 


\subsection{Heat network model}

191 For heat networks, the integrated hydraulic-thermal model developed in $[2,19]$ is used.

\subsubsection{Hydraulic model}

The continuity of flow is expressed as the mass flow entering a node being equal to the mass flow leaving the node plus the flow consumption at the node. For the entire hydraulic network, this is expressed as

$$
A_{h} \dot{\boldsymbol{m}}=\dot{\boldsymbol{m}}_{q}
$$

where $\boldsymbol{A}_{\boldsymbol{h}}$ is the heat network incidence matrix that relates the nodes to the branches. The subscript $h$ represents heat network. $\dot{\boldsymbol{m}}$ is the vector of the mass flow $(\mathrm{kg} / \mathrm{s})$ within each pipe. $\dot{\boldsymbol{m}}_{\boldsymbol{q}}$ is the vector of the mass flow $(\mathrm{kg} / \mathrm{s})$ through each node injected from a source or discharged to a load. The subscript $q$ represents nodal variables.

Head loss is the pressure change in meters due to the pipe friction. The loop pressure equation states that the sum of head losses around a closed loop must be equal to zero. For the entire hydraulic network, the loop pressure equation is expressed as

$$
\boldsymbol{B}_{\boldsymbol{h}} \boldsymbol{h}_{f}=0
$$

where $\boldsymbol{B}_{\boldsymbol{h}}$ is the loop incidence matrix that relates the loops to the branches; and $\boldsymbol{h}_{f}$ is the vector of the head losses (m). Each element of the $\boldsymbol{B}_{\boldsymbol{h}}$ is equal to: +1 , if the flow in a branch is the same direction as the definition; -1 , if the flow in a branch is the opposite direction as the definition; 0 , if a branch is not part of the loop.

The relation between the flow and the head losses along each pipe is

$$
\boldsymbol{h}_{f}=\boldsymbol{K}_{\boldsymbol{h}} \dot{\boldsymbol{m}}|\dot{\boldsymbol{m}}|
$$

where $\boldsymbol{K}_{\boldsymbol{h}}$ is the vector of the resistance coefficients of each pipe. $\boldsymbol{K}_{\boldsymbol{h}}$ is calculated from the length, the diameter and the roughness of a pipe. $\boldsymbol{K}_{\boldsymbol{h}}$ generally depends largely on the diameter of a pipe. More details are in [2, 19].

\subsubsection{Thermal model}

The thermal model is used to determine the temperatures at each node. There are three different temperatures associated with each node: the supply temperature $\left(T_{s}\right)$; the outlet temperature $\left(T_{\mathrm{o}}\right)$ and the return temperature $\left(T_{r}\right)$ [29]. The outlet temperature is defined as the temperature of the flow at the outlet of each node before mixing in the return network. Usually, the supply temperatures $T_{\mathrm{s}}$ at each source and the outlet temperatures $T_{\mathrm{o}}$ at each load are specified in the thermal model [30, 31].

The heat power at each node is related to the mass flow rate using equation [31, 32]

$$
\boldsymbol{\Phi}=C_{p} \dot{\boldsymbol{m}}_{\boldsymbol{q}}\left(\boldsymbol{T}_{s}-\boldsymbol{T}_{o}\right)
$$

where $\boldsymbol{\Phi}$ is the vector of heat power (MW) consumed or supplied at each node; $C_{p}$ is the specific heat of water ( $\mathrm{J}$ $\left.\mathrm{kg}^{-1}{ }^{\circ} \mathrm{C}^{-1}\right), C_{p}=4.182 \times 10^{-3} \mathrm{MJ} \mathrm{kg}^{-1}{ }^{\circ} \mathrm{C}^{-1}$.

Combining Equations (4) and (7), heat power equation is expressed as

$$
\boldsymbol{\Phi}=C_{p} \boldsymbol{A}_{\boldsymbol{h}} \dot{\boldsymbol{m}}\left(\boldsymbol{T}_{s}-\boldsymbol{T}_{o}\right)
$$

The temperature at the outlet of a pipe is calculated using equation [31-33]. 


$$
T_{\text {end }}=\left(T_{\text {start }}-T_{a}\right) e^{-\frac{\lambda L_{h}}{C_{p} \dot{m}}}+T_{a}
$$

218 where $T_{\text {start }}$ and $T_{\text {end }}$ are temperatures at the start node and the end node of a pipe $\left({ }^{\circ} \mathrm{C}\right) ; T_{a}$ is the ambient 219 temperature $\left({ }^{\circ} \mathrm{C}\right) ; \lambda$ is the overall heat transfer coefficient of each pipe per unit length $\left.\left(\mathrm{W} \mathrm{m}^{-1}{ }^{\circ} \mathrm{C}^{-1}\right)\right) ; L_{h}$ is the 220 length of each pipe $(\mathrm{m})$; and $\dot{m}$ is the mass flow rate $(\mathrm{kg} / \mathrm{s})$ within each pipe.

221 The temperature of water leaving a node with more than one incoming pipe is calculated as the mixture 222 temperature of the incoming flows using Equation (10). Temperature at the start of each pipe leaving the node is 223 equal to the mixture temperature at the node $[31,32]$.

$$
\left(\sum \dot{m}_{\text {out }}\right) T_{\text {out }}=\sum\left(\dot{m}_{\text {in }} T_{\text {in }}\right)
$$

224 where $T_{\text {out }}$ is the mixture temperature of a node $\left({ }^{\circ} \mathrm{C}\right) ; \dot{m}_{\text {out }}$ is the mass flow rate within a pipe leaving the node $(\mathrm{kg} / \mathrm{s}) ; T_{\text {in }}$ is the temperature of flow at the end of an incoming pipe $\left({ }^{\circ} \mathrm{C}\right)$; and $\dot{m}_{\text {in }}$ is the mass flow rate within a pipe coming into the node $(\mathrm{kg} / \mathrm{s})$.

\subsection{Gas network model}

228 The continuity of flow is expressed as

$$
A_{g} v_{g}=v_{q}
$$

229

230

231

232

233

234 235

236

237

where $\boldsymbol{A}_{\boldsymbol{g}}$ is the gas network incidence matrix that relates the nodes to the branches. $\boldsymbol{v}_{\boldsymbol{g}}$ is the vector of the gas flow rate within each pipe $\left(\mathrm{m}^{3} / \mathrm{h}\right)$. The subscript $g$ represents gas network. $\boldsymbol{v}_{\boldsymbol{q}}$ is the vector of the gas flow through each node injected from a source or discharged to a load. The subscript $q$ represents nodal variables.

The loop pressure equation states that the sum of pressure drop around a closed loop must be equal to zero. For the entire network, the loop pressure equation is expressed as

$$
\boldsymbol{B}_{\boldsymbol{g}} \Delta \boldsymbol{p}=0
$$

where $\boldsymbol{B}_{g}$ is the gas loop incidence matrix that relates the loops to the pipes; and $\Delta p$ is the pressure drop along each pipe (bar).

The relation between the flow and the pressure drop along each pipe is stated as [34]

$$
\Delta p=K_{g} v_{g}\left|v_{g}{ }^{k-1}\right|
$$

where $K_{g}$ is the resistance coefficient of each pipe, and the exponent $k$ is given by [34]

$$
k=\left\{\begin{array}{cc}
2 & \text { for low pressure networks operating between } 0 \sim 75 \mathrm{mbar} \\
1.848 & \text { for medium pressure networks operating between } 0.75 \sim 7.0 \mathrm{bar} \\
1.854 & \text { for high pressure networks operating above 7.0bar }
\end{array}\right.
$$

Gas distribution networks are typically operated at different pressure levels. In particular, the Great Britain distribution networks have three pressure tiers, namely, intermediate (2 to 7bar), medium (75mbar to 2 bar) and low (less than 75mbar) [35]. An exponent $k$ for medium pressure is used in the case study of Section 3.

The resistance coefficient $K_{g}$ is calculated as [34] 


$$
K_{g}=\left\{\begin{array}{cc}
11.70 \frac{L_{g}}{D_{g}^{5}} & \text { for low pressure networks } \\
27.24 \frac{L_{g}}{\varepsilon^{2} D_{g}^{4.848}} & \text { for medium pressure networks } \\
18.43 \frac{L_{g}}{\varepsilon^{2} D_{g}^{4.854}} & \text { for high pressure networks }
\end{array}\right.
$$

242 where $L_{g}$ is the pipe length $(\mathrm{m}) ; D_{g}$ is the pipe diameter $(\mathrm{mm}) . \varepsilon$ is the efficiency factor, which normally varies 243 between 0.8 and 1 for most gas pipes. In this work, $\varepsilon=0.98$.

244 The gas flow calculations are performed in the same way as for the hydraulic ones of heat networks, that is, 245 bringing together the combined continuity equation (11) and loop pressure equation (12)(13). The difference is 246 that $K_{\mathrm{g}}$ and the exponent $k$ as shown in Equation (14) replace $K_{h}$ and the exponent 2 in Equation (6).

247 Based on the pressure drop along each pipe $\Delta p$ in Equation (13), the vector of the pressure $\boldsymbol{p}$ at each node is 248 calculated as

$$
-\left(\boldsymbol{A}_{g}\right)^{T} \boldsymbol{p}=\Delta \boldsymbol{p}
$$

\subsection{Integrated modelling}

Based on the above, the combined active and reactive power (electricity), hydraulic and thermal (heat), and hydraulic (gas) equations for electrical, heat and gas networks can be expressed as

$$
\boldsymbol{F}(\boldsymbol{x})=\mathbf{0} \Rightarrow \begin{cases}\boldsymbol{P}^{s p}-\operatorname{Real}\left\{\boldsymbol{V}(\boldsymbol{Y V})^{*}\right\}=\mathbf{0} & \leftarrow \text { Active power } \\ \boldsymbol{Q}^{s p}-\operatorname{Imag}\left\{\boldsymbol{V}(\boldsymbol{Y} \boldsymbol{V})^{*}\right\}=\mathbf{0} & \leftarrow \text { Reactive power } \\ C_{p} \boldsymbol{A}_{\boldsymbol{h}} \dot{\boldsymbol{m}}\left(\boldsymbol{T}_{s}-\boldsymbol{T}_{o}\right)-\boldsymbol{\Phi}^{s p}=\mathbf{0}_{\leftarrow} & \leftarrow \text { Heat power } \\ \boldsymbol{B}_{\boldsymbol{h}} \boldsymbol{K}_{\boldsymbol{h}} \dot{\boldsymbol{m}}|\dot{\boldsymbol{m}}|=\mathbf{0} & \leftarrow \text { Loop pressure }- \text { heat } \\ \boldsymbol{C}_{s} \boldsymbol{T}_{s, \text { load }}-\boldsymbol{b}_{s}=\mathbf{0} & \leftarrow \text { Supply temperature } \\ \boldsymbol{C}_{r} \boldsymbol{T}_{r, \text { load }}-\boldsymbol{b}_{r}=\mathbf{0} & \leftarrow \text { Return temperature } \\ \boldsymbol{A}_{\boldsymbol{g}} \boldsymbol{v}_{\boldsymbol{g}}-\boldsymbol{v}_{\boldsymbol{q}}^{s p}=\mathbf{0} & \leftarrow \text { Gas flow } \\ \boldsymbol{B}_{\boldsymbol{g}} \boldsymbol{K}_{\boldsymbol{g}} \boldsymbol{v}_{\boldsymbol{g}}\left|\boldsymbol{v}_{\boldsymbol{g}}^{\boldsymbol{k}-\mathbf{1}}\right|=\mathbf{0} & \leftarrow \text { Loop pressure }- \text { gas }\end{cases}
$$

where $\boldsymbol{C}$ is a matrix of coefficients and $\boldsymbol{b}$ is a column vector of solutions formed in the thermal model (details are in [19]). The superscript $s p$ stands for specified (variables of nodal electrical, heat power and gas flows that are an input to each individual network model, and which are indicated as shaded). The vector of state variables is

$$
\boldsymbol{x}=\left[\begin{array}{l}
\boldsymbol{\theta} \\
|\boldsymbol{V}| \\
\dot{\boldsymbol{m}} \\
\boldsymbol{T}_{s, \text { load }} \\
\boldsymbol{T}_{r, \text { load }} \\
\boldsymbol{v}_{\boldsymbol{g}}
\end{array}\right]
$$

By using the multi-energy efficiency matrix $\mathcal{H}$, the model of conversion components are automatically incorporated in the terms $\boldsymbol{P}^{s p}, \boldsymbol{\Phi}^{s p}, \boldsymbol{v}_{\boldsymbol{q}}^{s p}$ of the multi-vector flow equations (17), which couple the three networks. Let us denote the matrix of end-use demand (e.g., electrical power and heat power) at the conversion components as $\boldsymbol{E}^{\text {out }}$, which is formed from the user input data. The matrix of input electrical power and gas flow at the conversion components is denoted as $\boldsymbol{E}^{\text {in }}$. The matrices $\boldsymbol{H}, \boldsymbol{E}^{\text {in }}$ and $\boldsymbol{E}^{\text {out }}$ have the same dimension, 
e.g., $N_{\text {con }} \times 3$ (see Table 1 ). The elements $E_{i j}^{i n}$ are equal to the elements $E_{i j}^{o u t}$ divided by the corresponding 261 element of the conversion efficiency matrix $\mathcal{H}_{i j}$.

$$
E_{i j}^{i n}=\left(\mathcal{H}_{i j}\right)^{-1} E_{i j}^{o u t}
$$

262 where $i$ is the global node number of conversion components, $j$ is the column index. In the example of Table 1, 263 for $\mathcal{H}$, the columns comprise ge, gh, eh (gas to electricity, gas to heat, electricity to heat, respectively). For $\boldsymbol{E}^{\text {in }}$, 264 the columns comprise gas, gas, electricity. For $\boldsymbol{E}^{\text {out }}$, the columns comprise electricity, heat, heat.

265 A flowchart describing the integration of the conversion component model into the multi-vector equations of the 266 three networks is shown in Figure 3.

Figure 3: Flowchart of the integration of the conversion component model into the multi-vector network equations

269 A simple example is used to illustrate the flowchart shown in Figure 3. Assuming that the conversion 270 components with global numbering 1,2, 3 and 4 are gas generator, CHP, heat pump, and gas boiler, respectively, 271 the steps are as follows:

272 Step 1) Output matrix and the conversion efficiency matrix are:

$$
\boldsymbol{E}^{\text {out }}=\left[\begin{array}{ccc}
\text { elec. } & \text { heat } & \text { heat } \\
E_{1, g e}^{\text {out }} & 0 & 0 \\
E_{2, g e}^{\text {out }} & E_{2, g h}^{\text {out }} & 0 \\
0 & 0 & E_{3, \text { e h }}^{\text {out }} \\
0 & E_{4, g h}^{\text {out }} & 0
\end{array}\right], \quad \mathcal{H}=\left[\begin{array}{ccc}
H_{g} \eta_{g e}^{1} & 0 & 0 \\
H_{g} \eta_{g e}^{2} & H_{g} \eta_{g h}^{2} & 0 \\
0 & 0 & \eta_{\text {eh }}^{3} \\
0 & H_{g} \eta_{g h}^{4} & 0
\end{array}\right]
$$

273 Step 2) Input matrix of conversion components are: 


$$
\boldsymbol{E}^{i n}=\left[\begin{array}{ccc}
\text { gas } & \text { gas } & \text { elec. } \\
E_{1, g e}^{i n} & 0 & 0 \\
E_{2, g e}^{i n} & E_{2, g h}^{i n} & 0 \\
0 & 0 & E_{3, e h}^{i n} \\
0 & E_{4, g h}^{i n} & 0
\end{array}\right]
$$

274 Step 3) From Equations (20) (21), the specified electrical power of a conversion component is equal to electric 275 power generated from gas $\boldsymbol{E}_{i, g e}^{\text {out }}$ minus electric power converted to heat $\boldsymbol{E}_{i, e h}^{i n}$. The specified heat power and gas 276 flows of a conversion component are expressed similarly.

$$
\begin{array}{ll}
P_{i}^{\text {con }}=E_{i, g e}^{\text {out }}-E_{i, \text { eh }}^{\text {in }}, & i=1,2, \ldots, N_{\text {con }} \\
\Phi_{i}^{\text {con }}=E_{i, g h}^{\text {out }}+E_{i, e h}^{\text {out }}, & i=1,2, \ldots, N_{\text {con }} \\
v_{q_{i} i}^{\text {con }}=-E_{i, g e}^{\text {in }}-E_{i, g h}^{\text {in }}, & i=1,2, \ldots, N_{\text {con }}
\end{array}
$$

277 where the index $i$ is the global numbering of conversion components and the subscript con represents conversion 278 components.

279 Step 4) The mapping procedure of global numbering of energy vectors as shown in Equation (22) to local 280 numbering of multi-energy networks is illustrated in Figure 4. For instance, the values $P_{2}^{\text {con }}, \Phi_{2}^{\text {con }}, v_{q 2}^{\text {con }}$ of a 281 conversion component with global numbering node 2 are mapped to electrical power of node 5 in the electrical 282 network $P_{e 5}^{s p}$, heat power of node 3 in the heat network $\Phi_{h 3}^{s p}$ and gas flow of node 4 in the gas network $v_{q_{-} g 4}^{s p}$. 283 The same mapping is applied for the nodes of global numbering 1,3 , and 4.

Figure 4: Schematic of the mapping of global numbering of energy vectors to local numbering of multi-energy networks

Therefore, the combined electrical power, heat power and gas flows of the three networks using local node 287 numbering are: 


$$
\left[\begin{array}{c}
P_{e 1}^{s p} \\
P_{e 2}^{s p} \\
P_{e 3}^{s p} \\
P_{e 4}^{s p} \\
P_{e 5}^{s p}
\end{array}\right]=\left[\begin{array}{c}
P_{n o n, e 1}^{s p} \\
P_{n o n, e 2}^{s p} \\
P_{3}^{c o n}+P_{n o n, e 3}^{s p} \\
P_{1}^{c o n}+P_{n o n, e 4}^{s p} \\
P_{2}^{c o n}+P_{n o n, e 5}^{s p}
\end{array}\right], \quad\left[\begin{array}{c}
\Phi_{h 1}^{s p} \\
\Phi_{h 2}^{s p} \\
\Phi_{h 3}^{s p} \\
\Phi_{h 4}^{s p} \\
\Phi_{h 5}^{s p}
\end{array}\right]=\left[\begin{array}{c}
\Phi_{n o n, h 1}^{s p} \\
\Phi_{4}^{c o n}+\Phi_{n o n, h 2}^{s p} \\
\Phi_{2}^{c o n}+\Phi_{n o n, h 3}^{s p} \\
\Phi_{n o n, h 4}^{s p} \\
\Phi_{3}^{c o n}+\Phi_{n o n, h 5}^{s p}
\end{array}\right], \quad\left[\begin{array}{c}
v_{q_{-g}}^{s p} \\
v_{q_{-g}}^{s p} \\
v_{q_{-g}}^{s p} \\
v_{q_{-g}}^{s p} \\
v_{q_{-} g 5}^{s p}
\end{array}\right]=\left[\begin{array}{c}
v_{q_{n o n}, g 1}^{s p} \\
v_{q_{n o n}, g 2}^{s p} \\
v_{q 4}^{c o n}+v_{q_{n o n}, g 3}^{s p} \\
v_{q 2}^{c o n}+v_{q_{n o n}, g 4}^{s p} \\
v_{q 1}^{c o n}+v_{q_{n o n}, g 5}^{s p}
\end{array}\right]
$$

288 where the subscript "non" represents non-conversion components (e.g., load). The shaded elements are variables 289 of conversion components. For instance, in line with what explained above, heat power of node 2 in the heat 290 network $\Phi_{h 2}^{s p}$ and gas flow of node 3 in the gas network $v_{q_{-} g 3}^{s p}$ are all taken from the values $\Phi_{4}^{c o n}, v_{q 4}^{c o n}$ of a 291 conversion component with global numbering node 4.

292 The combined power flow equations (17) are solved simultaneously by means of the Newton-Raphson method. 293 The iterative form of the Newton-Raphson method is

$$
\boldsymbol{x}^{(i+1)}=\boldsymbol{x}^{(i)}-\boldsymbol{J}^{-1} \Delta \boldsymbol{F}(\boldsymbol{x})
$$

294 where $i$ is the iteration number, $\boldsymbol{x}$ the vector of state variables, $\Delta \boldsymbol{F}$ the vector of total mismatches that is the left 295 side of Equation (17), and $\boldsymbol{J}$ the Jacobian matrix, that is, the first derivative of $\Delta \boldsymbol{F}$ with respect to $\boldsymbol{x}$. Details as to 296 how to form the Jacobian $\boldsymbol{J}$ can be found in [19].

\section{3. Case study description: the University of Manchester campus}

\section{$298 \quad 3.1$ Description of district energy networks}

299 Data were gathered to apply the model to a real multi-vector district at the University of Manchester.

\section{$300 \quad$ 3.1.1 Electricity network}

The University of Manchester owns a $6.6 \mathrm{kV}$ distribution network fed from a $33 / 6.6 \mathrm{kV}$ transformer connected to busbar 13 (Figure 5). The electrical power is supplied to electrical loads through a $6.6 / 0.415 \mathrm{kV}$ transformer at each feeder. The building loads presented spatially on a map for one ring main only are shown in Figure 5. The network is operated in open ring at node 6.The electrical loads at each building are known from monitored data. 


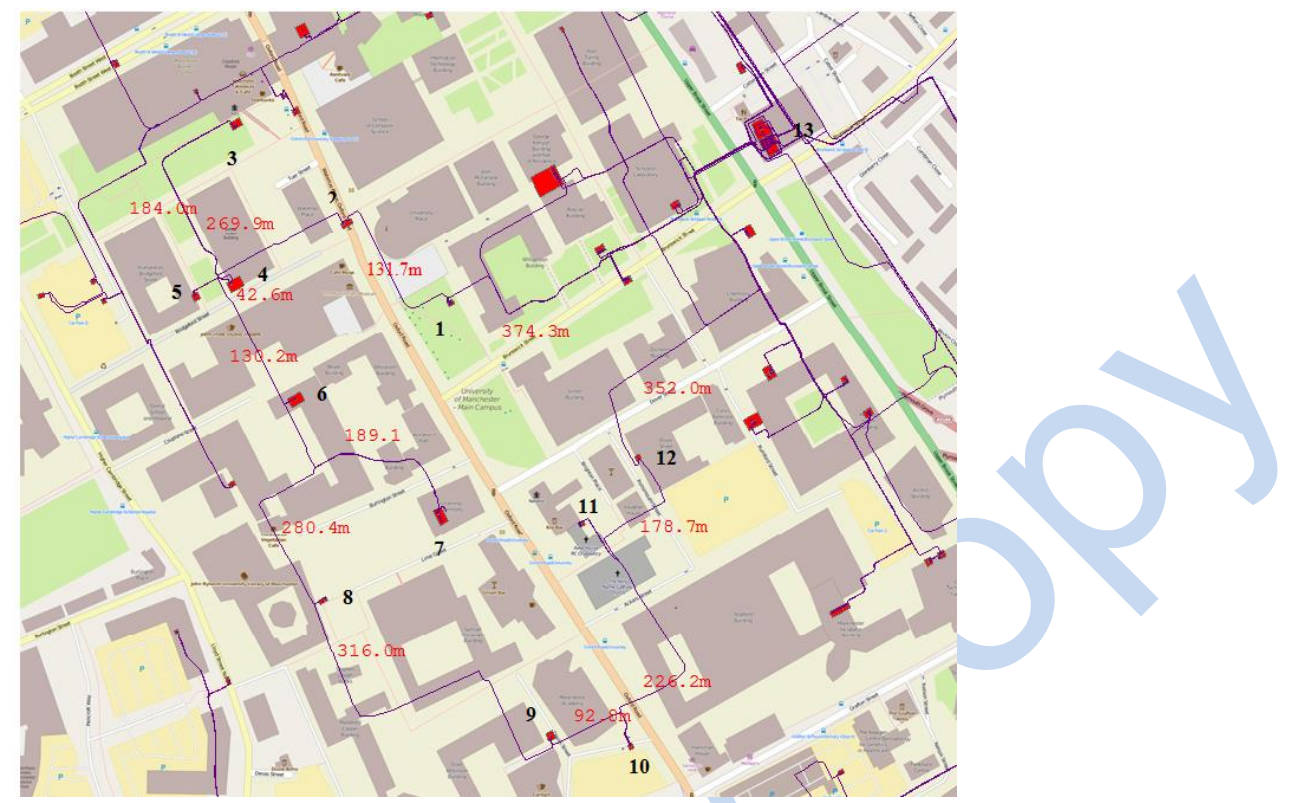

Figure 5: Map of buildings served by the electrical network

It is considered that the impedance of $300 \mathrm{~mm}^{2}$ cables is $0.1000+\mathrm{j} 0.0770 \Omega / \mathrm{km}$ [36], the $33 / 6.6 \mathrm{kV} 15 \mathrm{MVA}$ transformer has an impedance of $18 \%$ and $\mathrm{X} / \mathrm{R}$ ratio of 15 [36], and the power factor of each electrical load is assumed to be $p . f .=0.94$. The per unit base apparent power is taken as $1 \mathrm{MVA}$ and the base voltage is $6.6 \mathrm{kV}$.

\subsubsection{Heat network}

The Manchester district includes heat networks whereby centralised boiler plants deliver heat to multiple buildings through buried pipework. A schematic diagram of the plant rooms and buildings served by the network presented spatially on a map is shown in Figure 6. There are two gas boilers currently in the system: one boiler is connected to Precinct building at node 1, which provides the heat slack node; the other boiler is connected to Ellen Wilkinson building at node 20. The heat loads are known from monitored data.

316 It is assumed that the supply temperature at each source is $T_{s, \text { source }}=85^{\circ} \mathrm{C}$, outlet temperature (return temperature 317 before mixing) at each heat load is $T_{o, \text { load }}=70^{\circ} \mathrm{C}$, ambient temperature (of the ground) is $T_{a}=7^{\circ} \mathrm{C}$. Capacities of central gas boilers are 19.2MW at Source 1 and 4.8MW at Source 2, with efficiency of $79.2 \%$ in both cases. 


\section{1}

322

323

324

\subsubsection{Gas network}

A schematic diagram of the buildings served by the gas network presented spatially on a map is shown in Figure 7. Heat loads for each building are supplied by gas boilers, with two large scale boilers connected to the heat network, plus other smaller boilers, with efficiency assumed equal to 83\%, directly supplying buildings.

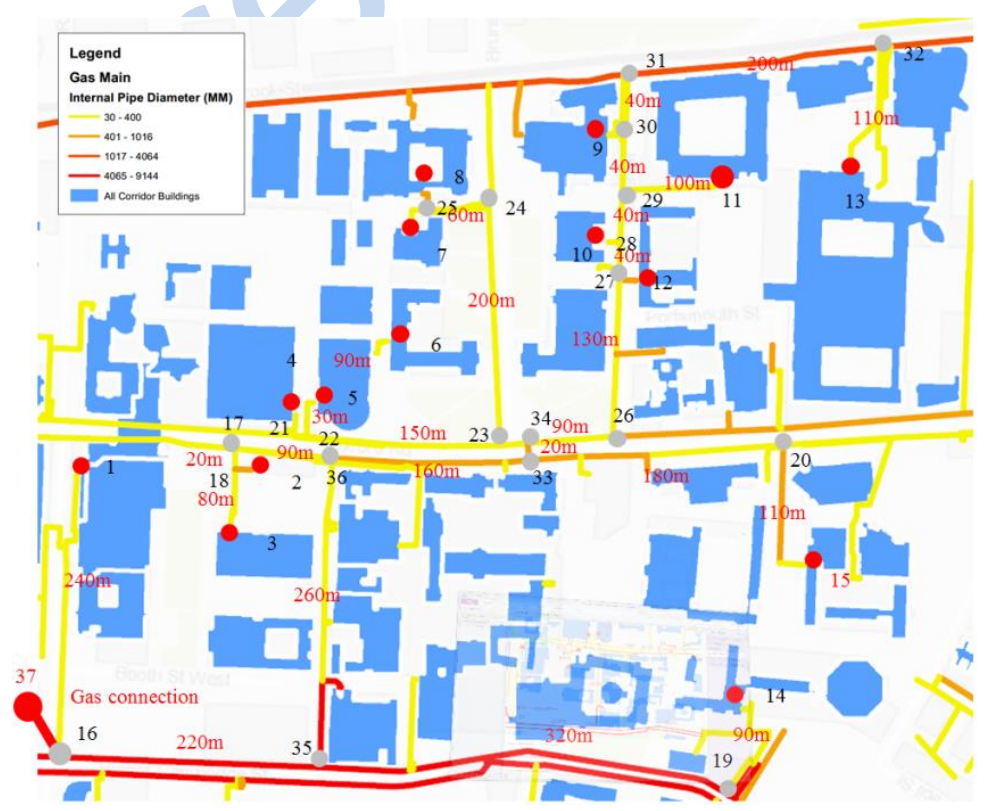

Figure 7: Schematic diagram of buildings served by the gas network (Source: ARUP) 


\subsection{Time series input data}

\subsection{Energy prices and carbon content}

Grid electricity and natural gas prices as shown in Table 2 are based on 2013 from National grid [38]. It has to be pointed out that the objective of this paper is primarily to build a multi-energy integrated load flow model. From this, several applications can be carried out, for instance, to determine cash flows starting from energy flows and based on incumbent energy prices. For the sake of example, grid electricity and natural gas prices are assumed static in the case studies conducted here. However, dynamic prices and other forms of tariffs might be readily applied as well.

The carbon content for natural gas and grid electricity is also shown in Table 2 [39]. For carbon content of grid electricity, $27 \mathrm{~g} / \mathrm{kWh}$ is consistent with the midrange of Pöyry projections for 2050 [40]. On the other hand, $450 \mathrm{~g} / \mathrm{kWh}$ is close to current UK average emission factor. Again, in line with what done with energy prices, static emission factors have been applied here for illustrative purposes, but the time-series multi-energy load flow model proposed here is of course fully consistent with and could be applied to other approaches for emission accounting, for instance with hourly variation.

Table 2: Energy prices and carbon content

\begin{tabular}{c|c|c|c|c|c}
\hline \multirow{2}{*}{ Input } & \multicolumn{3}{|c|}{ Energy prices } & \multicolumn{2}{c}{ Carbon content } \\
\cline { 2 - 6 } & Grid electricity & Electricity (export) & Natural gas & Natural gas & Grid electricity \\
\hline Value/Range & $50.6 £ / \mathrm{MWh}$ & $\begin{array}{c}80 \% \text { of grid electricity } \\
\text { price [16] }\end{array}$ & $23.6 £ / \mathrm{MWh}$ & $0.204 \mathrm{~kg}_{\mathrm{CO} 2} / \mathrm{kWh}$ & $0.027-0.45 \mathrm{~kg}_{\mathrm{CO} 2} / \mathrm{kWh}$ \\
\hline
\end{tabular}

\subsection{Scenarios}

350 For heat load, buildings in the district heating network are supplied by district level conversion components, other 351 buildings are supplied by local conversion components fuelled by gas or powered by electricity. At present, the 
heat network utilises boilers as the heat-generating technology, not CHP or heat pumps. Utilising or expanding the heat network with the use of CHP or large scale heat pumps may presents an opportunity for increasing the efficiency of heat and electricity supply to the district. The following Scenarios as shown in Table 3 are therefore conducted:

Table 3: Scenarios with the various conversion components at different levels

\begin{tabular}{l|lrl}
\hline & District-level supply & + & Building-level supply \\
\hline Scenario 1 & District level gas boilers & + & Local gas boilers \\
\hline Scenario 2 & District level gas boilers & + & Local heat pumps \\
\hline Scenario 3 & District level CHP & + & Local gas boilers \\
\hline Scenario 4 & District level CHP & + & Local heat pumps \\
\hline Scenario 5 & District level CHP & + & Local CHP \\
\hline Scenario 6 & District level heat pumps & + & Local heat pumps \\
\hline
\end{tabular}

The Scenarios against conversion components at both district level and local level are also summarised in Table 4.

Table 4: Mapping of Scenarios through various conversion components

\begin{tabular}{|c|c|c|c|c|}
\hline \multirow{2}{*}{\multicolumn{2}{|c|}{ Scenario }} & \multicolumn{3}{|c|}{ District level conversion components } \\
\hline & & Gas boiler & $\mathrm{CHP}$ & Heat pump \\
\hline \multirow{3}{*}{$\begin{array}{l}\text { Local level } \\
\text { conversion } \\
\text { components }\end{array}$} & Gas boiler & 1 & 3 & \\
\hline & CHP & & 5 & \\
\hline & Heat pump & 2 & 4 & 6 \\
\hline
\end{tabular}

Scenario 1 is the original real case, in which gas boilers at both district and local levels are used. To investigate the impact of heat pumps, the local gas boilers are replaced by local heat pumps in Scenario 2. To investigate the impact of CHP, the district level gas boilers in the heat network in Scenarios 1 and 2 are replaced by district level CHP units in Scenarios 3 and 4. Furthermore, two extreme Scenarios are conducted to exam the impact of high penetration of CHP and heat pumps. Scenario 5 has full penetration of CHP at both district and local levels. Scenario 6 has full penetration of heat pumps at both district and local levels. In Scenario 6, heat is all electrified and there is no gas network.

The parameters of conversion components in the six Scenarios in Table 4 are described as follows:

- The district level CHP units are gas turbines with nominal electrical capacity of 5.5MW, electrical efficiency of $27.7 \%$ and heat-to-power ratio of 1/0.66 [41]. One CHP unit at Source 1 is connected to node 3 of the electrical network. This CHP unit provides the heat slack and produces electricity accordingly. The other CHP unit at Source 2 is connected to node 9 of the electrical network. Any surplus or deficit in electrical power is supplied from the main grid.

- The $C O P$ of local heat pumps is assumed $C O P=3$ and the size is varied according to the peak heat load of each building. The $C O P$ of district level heat pumps is also assumed $C O P=3$.

- The electrical capacity of local gas reciprocating CHP engines is $800 \mathrm{~kW}$, with electrical efficiency equal to $35 \%$ and heat-to-power ratio of $1 / 0.79$ [41].

- The electricity generated by local CHP or consumed by local heat pumps is associated to the local substations in the electricity network. This association is determined based on the nodes in closer proximity. 
Since the scope of this paper is load flow analysis and simulation rather than optimal dispatch, the optimal operating strategy of CHP, gas boilers or heat pumps is not investigated and is left to future work.

\section{Case study results and Sankey diagrams}

The running time for a snapshot for the integrated multi-carrier energy network analysis is less than 0.02 seconds. Results of operational variables for electrical, heat and gas networks for a typical weekday are presented below, along with Sankey energy flows, $\mathrm{CO}_{2}$ emissions and operational costs for each scenario. The interactions between the electricity, heat and gas networks through conversion components are thus clearly demonstrated.

\subsection{Electrical network}

Electrical power generation from two Sources and main grid for each Scenario is shown in Figure 9.

- Since there is no interaction between electricity and other networks in (a), the imported grid electricity profile

- The impact of district level CHP and heat pumps is shown in (c) (d) (e) (f). There is a peak of grid electricity follows the profile shape of electrical load as shown in Figure 8.

during the peak heat load period 5:00-7:30 from the heat network. This is because district level CHP units generate more heat at this period and more electricity is exported to the grid. Likewise, district level heat pumps produce more heat at these periods and thus more electricity is imported from the grid.

- The impact of local CHP and heat pumps is shown in (b) (d) (e) (f). There is a peak of grid electricity during the peak heat load period 13:00-14:30 from the gas network. This is because during these periods, more electricity is produced by local CHP or consumed by local heat pumps to meet the heat load requirement.

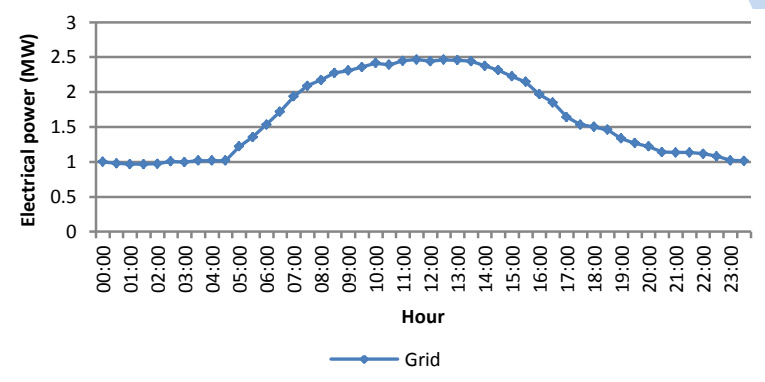

(a) Scenario 1: District level gas boilers + local gas boilers

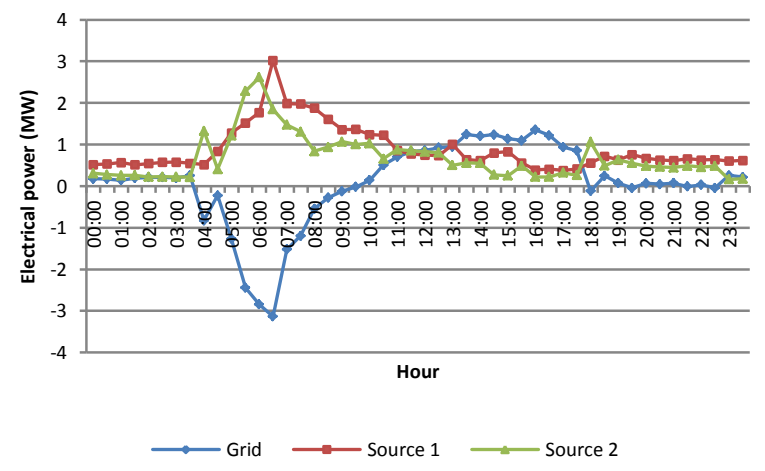

(c) Scenario 3: District level CHP + local gas boilers

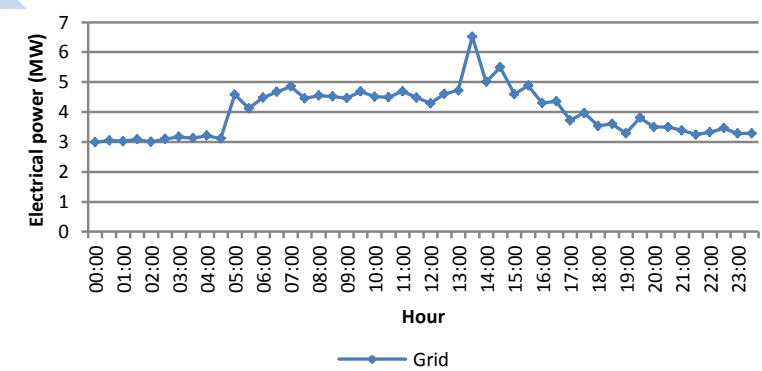

(b) Scenario 2: District level gas boilers + local heat pumps

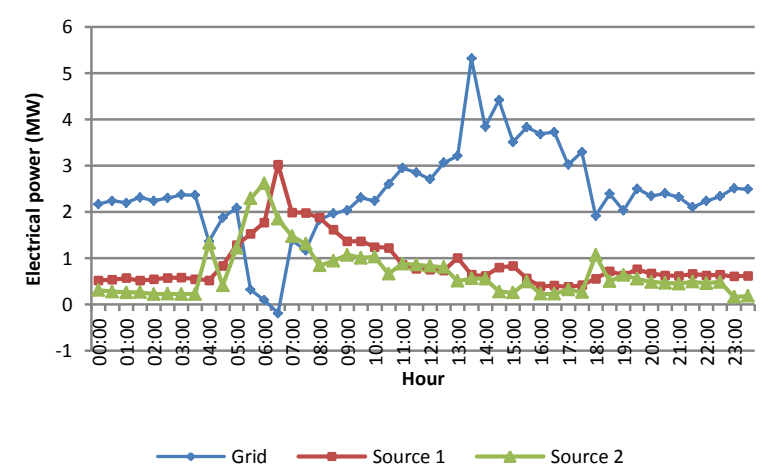

(d) Scenario 4: District level CHP + local heat pumps 


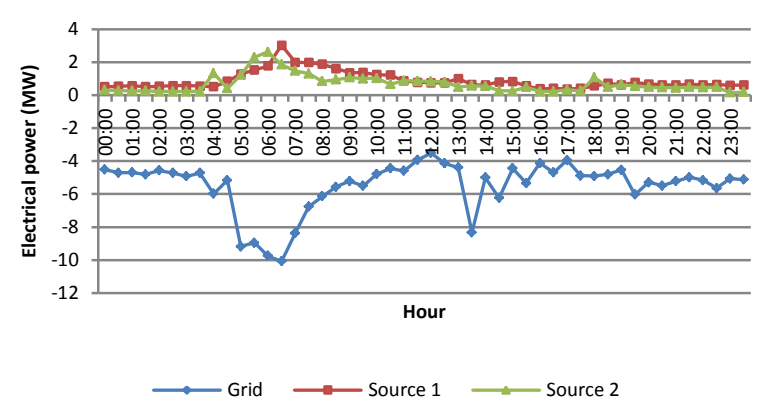

(e) Scenario 5: District level CHP + local CHP

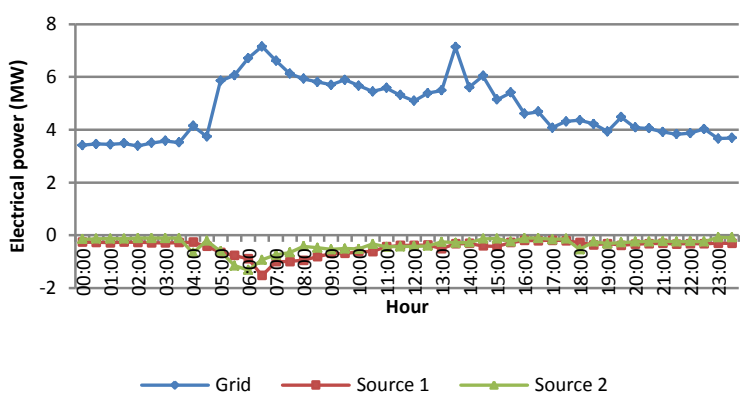

(f) Scenario 6: District level heat pumps + local heat pumps

Figure 9: Electrical power generation in half-hourly time series

Voltage magnitudes at each node in half-hourly time series are shown in Figure 10. The detailed differences in results for the six considered scenarios depend on a number of parameters and multi-energy supply technologies. In particular, by changing local electrical generation (e.g., by CHP) or consumption (e.g., by heat pumps) levels, different effects on voltage and losses profiles, which are key variables in electrical networks, can be appreciated.

- Since there is no interaction between electricity and other networks in (a), the voltage profile follows the profile shape of electrical load as shown in Figure 8.

- The highest levels of voltage drops occur during the peak heat load period 13:00-14:30 from the gas network, as shown in (b) (f). This is because local heat pumps shift heat load from gas to electricity.

- The highest levels of voltage drops occur during the peak heat load period 5:00-7:30 from the heat network, as shown in (c)-(e). This is because district level CHP units generate more heat at this period.

- Comparing (a) and (c) (e), it is shown that CHP mitigates voltage drop. Comparing (a) and (b) (d) (f), it is shown that heat pumps increase voltage drop. The full penetration of heat pumps in Scenario 6 leads to a noticeable voltage drop to $0.983 p$.u. In absolute terms, this is not significant and still far from minimum accepted voltage drops for medium voltage distribution networks, which is in the order of $6 \%$ [42], due to the fact that the case study network is very robust. However, it may be expected that for other networks voltage drop may be more significant, and the model is well suitable to capture this while considering interaction with other energy networks too.

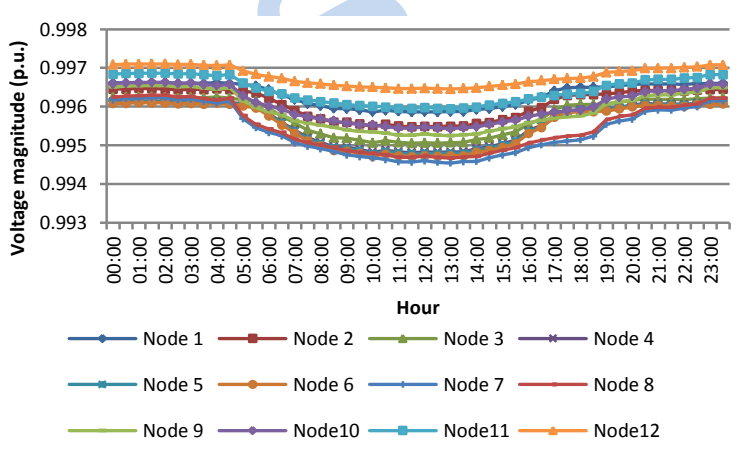

(a) Scenario 1: District level gas boilers + local gas boilers

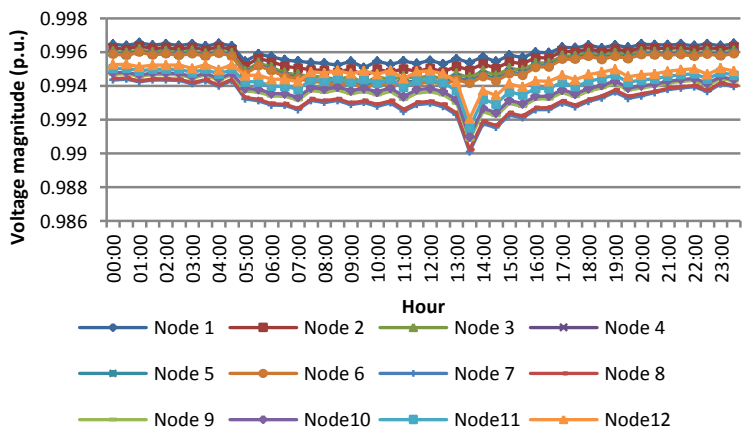

(b) Scenario 2: District level gas boilers + local heat pumps 


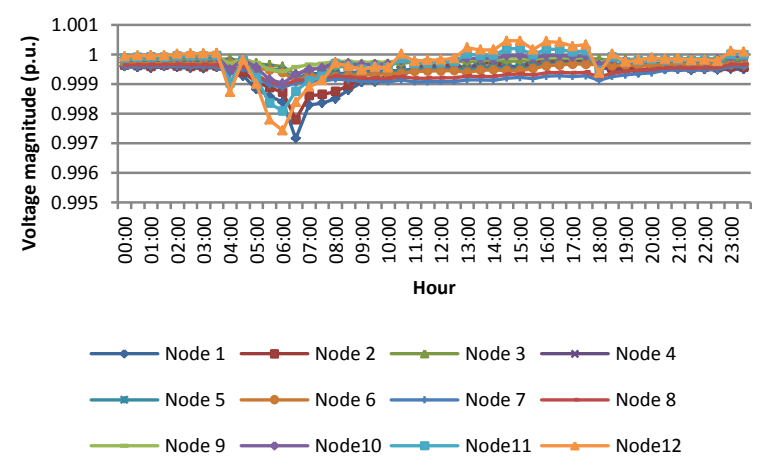

(c) Scenario 3: District level CHP + local gas boilers

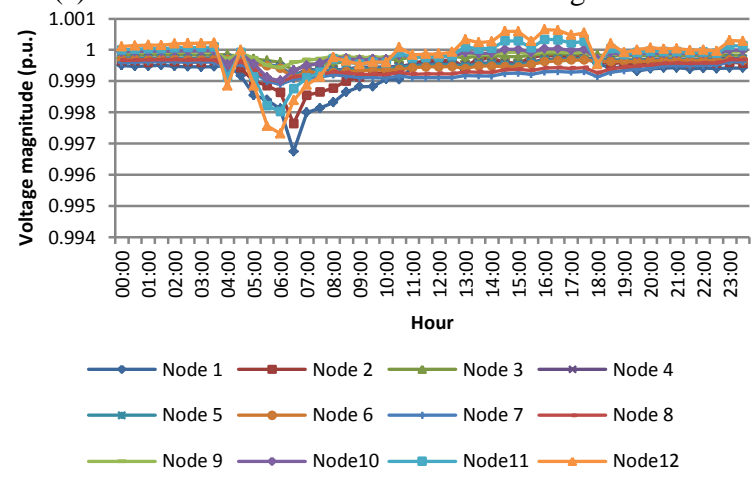

(e) Scenario 5: District level CHP + local CHP

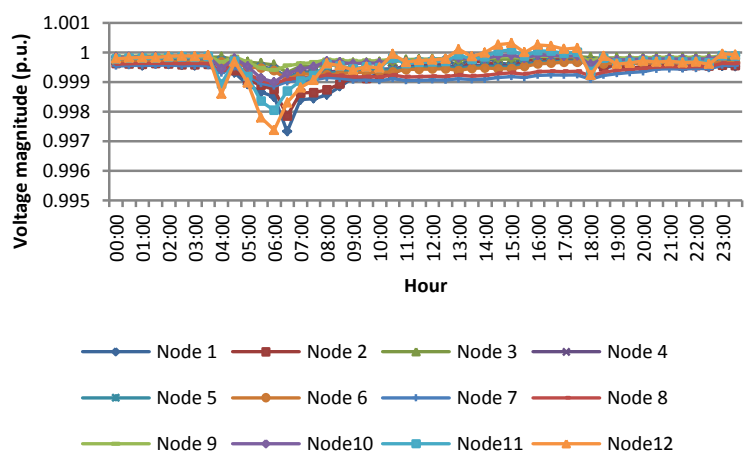

(d) Scenario 4: District level CHP + local heat pumps

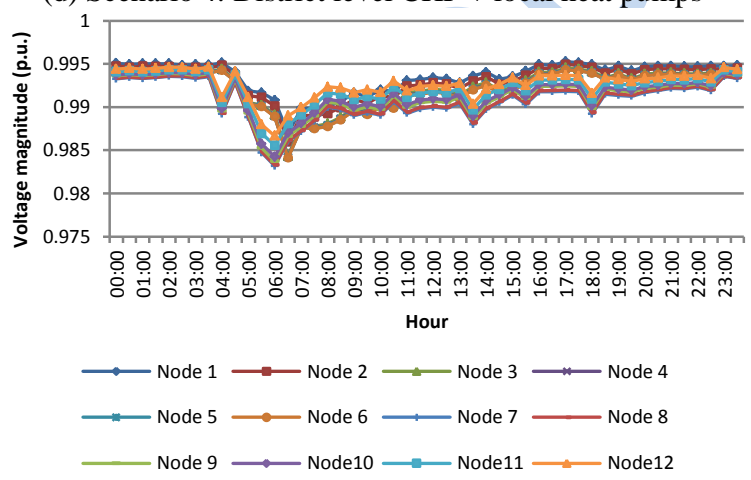

(f) Scenario 6: District level heat pumps + local heat pumps

Figure 10: Voltage magnitude at each node in half-hourly time series

415 Electrical power losses for each Scenario are shown in Figure 11.

416 - In Scenario 1, the highest levels of electrical losses arise during electrical peak load hours since there is no interaction between electrical and other networks. Electrical losses follow the expected profile shape of electricity from main grid as shown in Figure 9.

- The highest levels of electricity losses typically occur during heat peak load periods in Scenarios 3-6. This is due to the presence of CHP and/or heat pumps, that may cause significant counter-flows or higher peak loads, respectively. In particular, high penetration of $\mathrm{CHP}$ and/or heat pumps increases electricity losses markedly as shown in Scenarios 5 and 6.

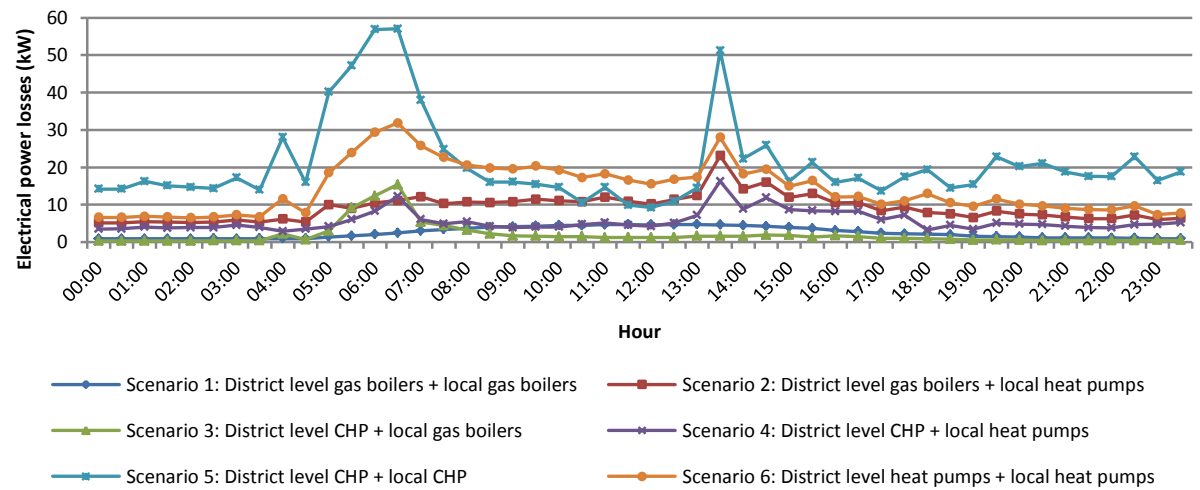




\subsection{Heat network}

426 The results of heat network simulations include: heat power generation, supply and return temperatures and heat losses. The results of all scenarios are the same because the heat load and generation for each scenario are the same. The energy network is operated in grid-connected mode and any surplus or deficit in electrical and heat power is ultimately converted to electricity supplied from the main grid.

Heat generation from two Sources is shown in Figure 12. Heat generation of Source 2 is assumed as an input. The input is determined based on the loads in close proximity. Source 1 provides the heat slack. The heat generation profile follows the profile of the heat load from the heat network as shown in Figure 8.

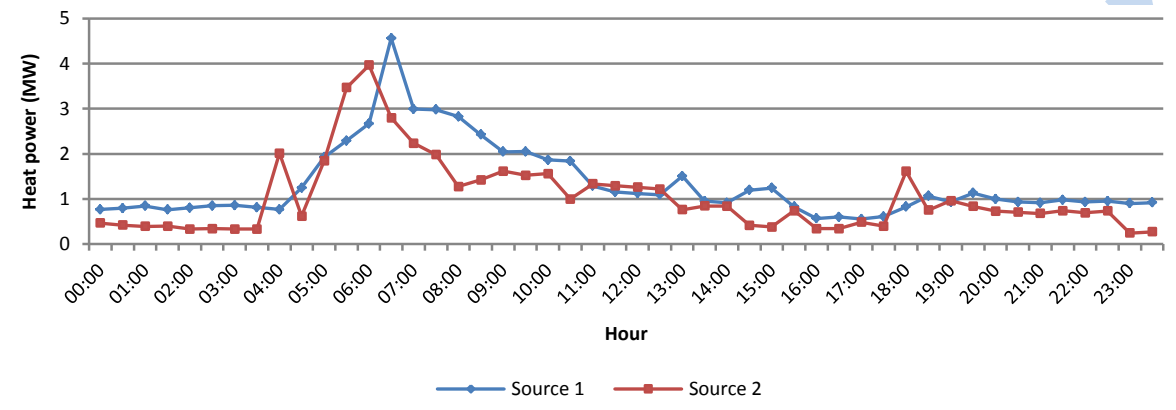

Figure 12: Heat generation from two Sources in half-hourly time series

Supply temperatures at each node in half-hourly time series are shown in Figure 13. The largest drop of supply temperature at node 19 during 0:00-04:30 and 16:00-23:30 is due to assumed zero heat load at this node during those periods. The other low supply temperatures occur at node 6 , which has nearly zero heat load. These low temperatures occur due to very low heat load, which leads to low mass flow rate and then larger temperature drop.

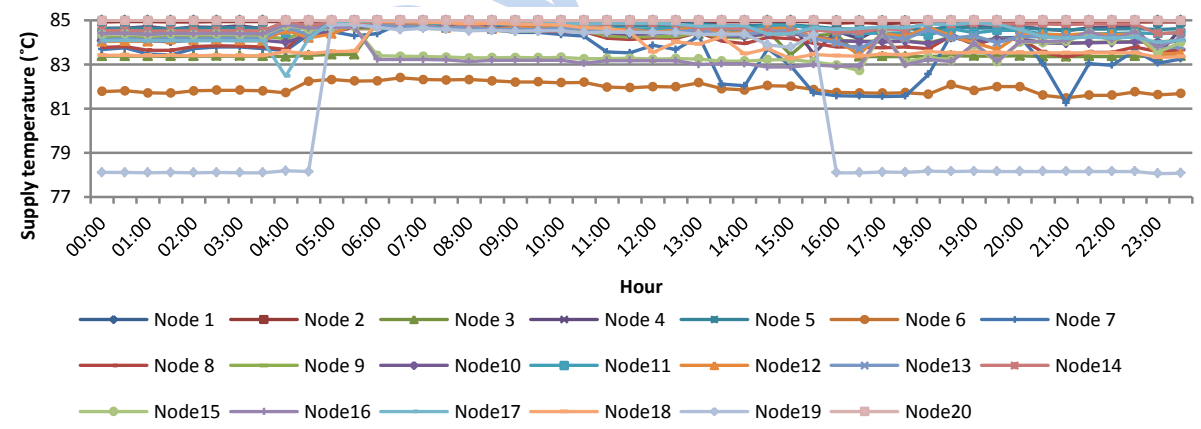

Figure 13: Supply temperature at each node in half-hourly time series

Heat losses are shown in Figure 14. Differently from electrical losses, heat losses do not follow the profile shape of the heat load. This is because heat losses are basically proportional to the mass flow rate and the temperature drop across pipelines. When the heat load is larger, the mass flow rate in a pipe is larger. A larger mass flow rate in turn leads to smaller temperature drop, which is the temperature difference between the start and the end of a pipe. It is thus seen that heat losses, determined by the product of larger mass flow rate and smaller temperature difference, may increase or decrease depending on the specific conditions. 


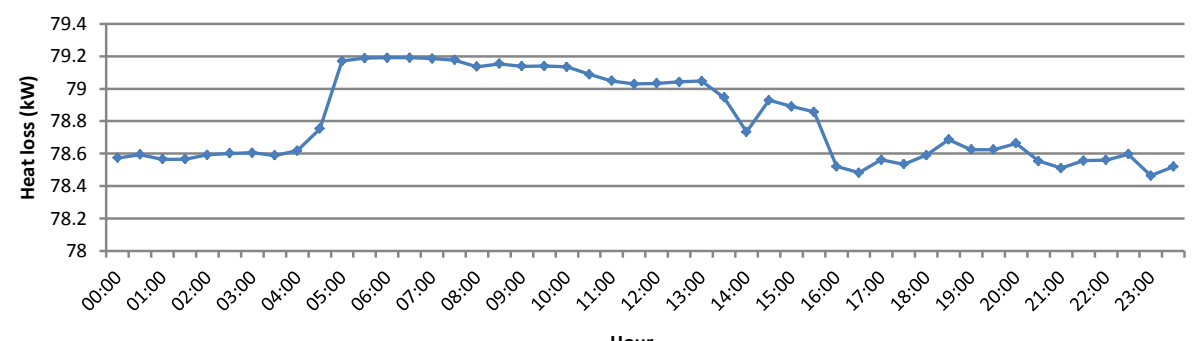

Figure 14: Heat losses in half-hourly time series

\subsection{Gas network}

Results of Scenarios 1-5 are presented since there is no gas network in Scenario 6.

Gas flow rates from the gas injection point are shown in Figure 15. The profile follows the expected profile shape of heat load as shown in Figure 8. At peak heat load times (5:00-7:30 and 13:00-14:30), the largest amount of gas is injected to meet more heat consumption. The largest gas injection occurs in Scenario 5, followed by Scenario 3 because the thermal efficiencies of local CHP and district level CHP are lower than that of gas boilers (while of course CHP are also producing electricity at the same time).

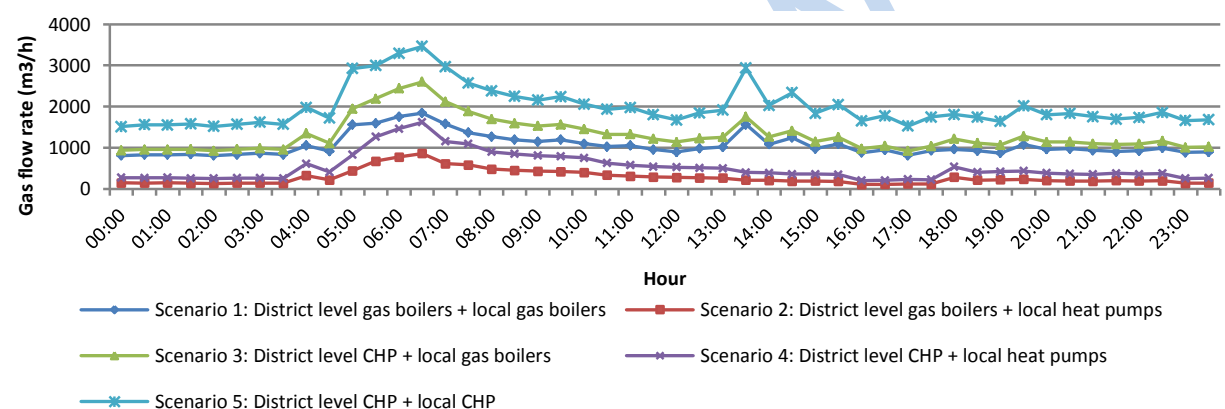

Figure 15: Gas flow rate from the injection point in half-hourly time series

Gas relative pressures at the injection point in half-hourly time series are shown in Figure 16. Gas distribution losses are shown in Figure 17. The profiles of gas pressure and gas losses follow the total heat load profile as shown in Figure 8. At peak heat load times (5:00-7:30 and 13:00-14:30) from the gas network, gas pressure and losses are largest due to the requirement to meet more heat consumption. In Scenarios 5, the gas pressure and losses are largest when the amount of injected gas flow is largest as shown in Figure 15. It can be seen that in Scenario 5 with full penetration of CHP at both district and local levels, the large gas flows lead to significant pressure and energy losses, even if there was no problem on the electrical network. The gas flows may exceed the capacity of pipes and in fact pressures higher than the standard network pressure would be required, showing infeasibility of this solution and the importance of considering multiple energy networks simultaneously. 


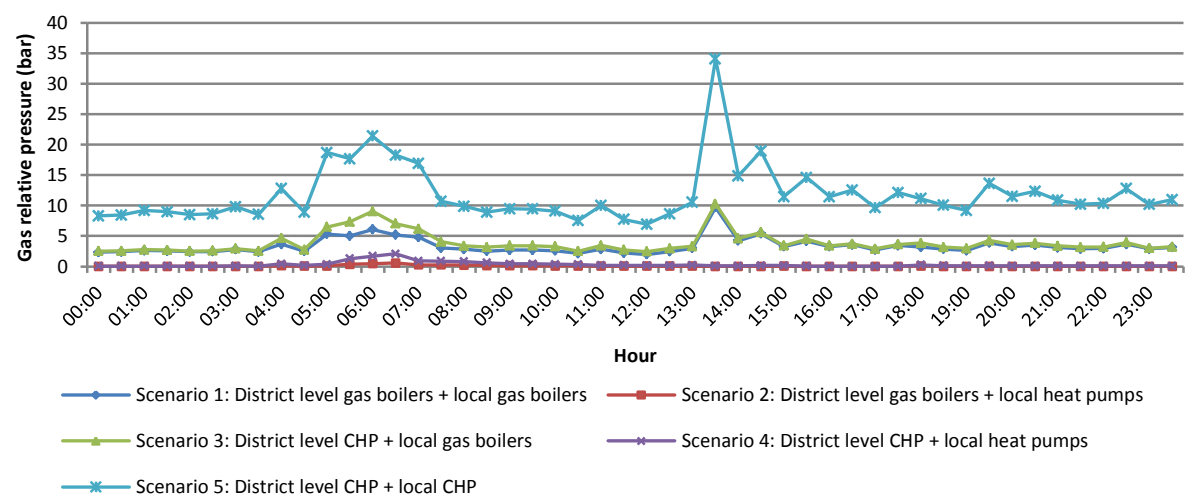

Figure 16: Gas relative pressure at the injection point in half-hourly time series

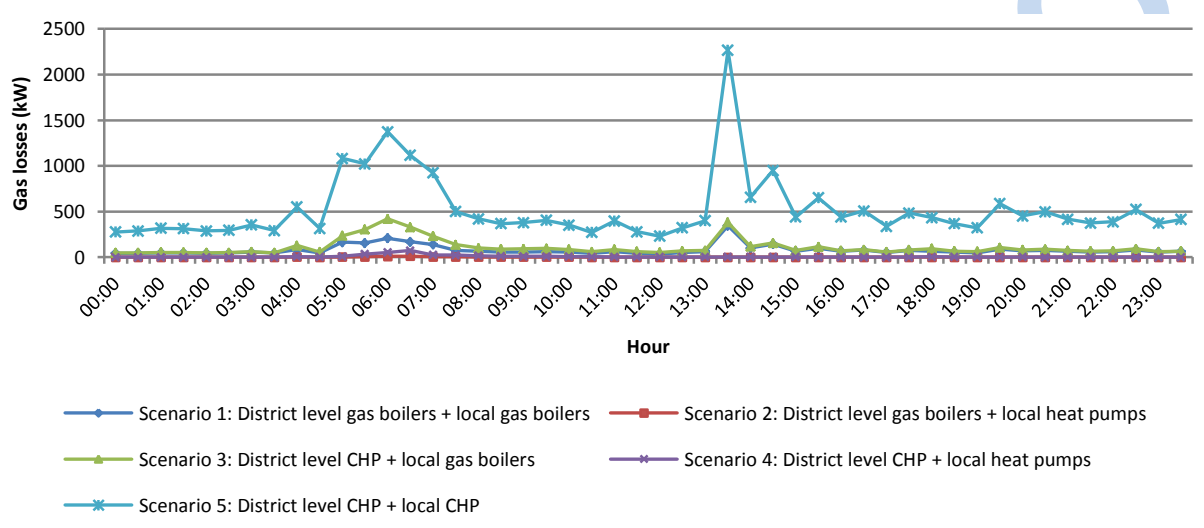

Figure 17: Gas losses in half-hourly time series

\section{$471 \quad 4.4$ Flows of energy}

472 Detailed Sankey diagrams of multi-network energy flows for each Scenario are shown in Figure 18, in which 473 the values display the total energy flows (MWh) in 24 hours in one typical day. The diagram visualises a map of the multi-vector energy flows across the three networks from supply to demand through energy conversion technologies. It shows the amount of natural gas fuel input and imported or exported grid electricity, which also allows performing calculations of carbon emissions and energy costs automatically. The diagrams clearly visualise the impact of various conversion components through comparing energy flows of different Scenarios, which is eventually useful for multi-energy network design and operational purposes. 


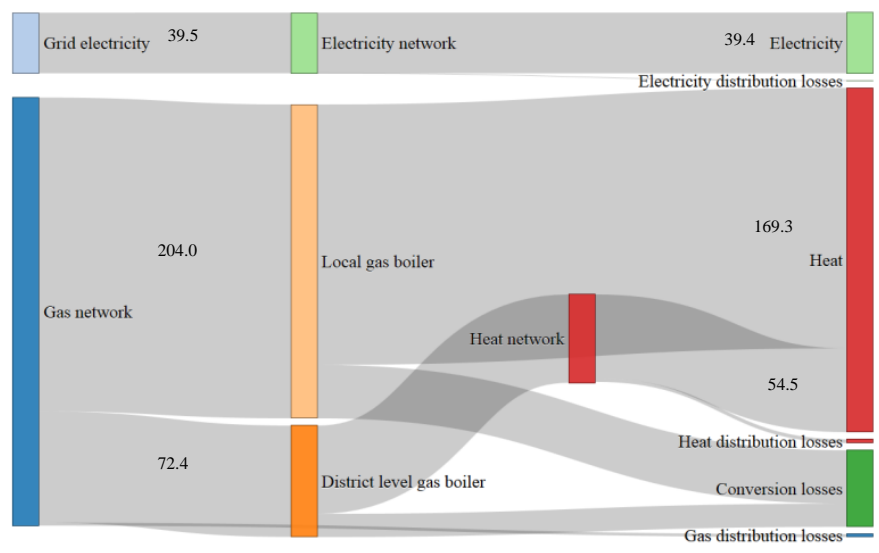

(a) Scenario 1: District level gas boilers + local gas boilers

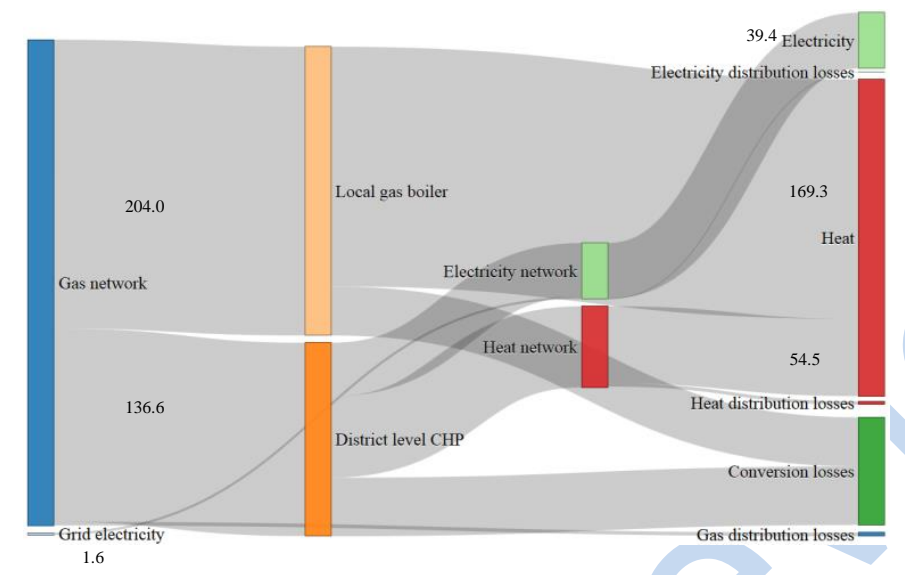

(c) Scenario 3: District level CHP + local gas boilers

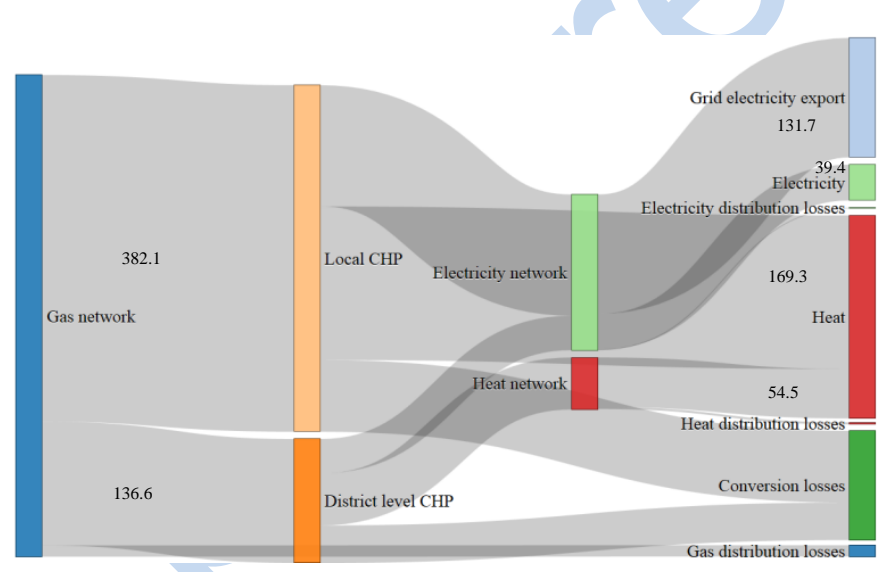

(e) Scenario 5: District level CHP + local CHP

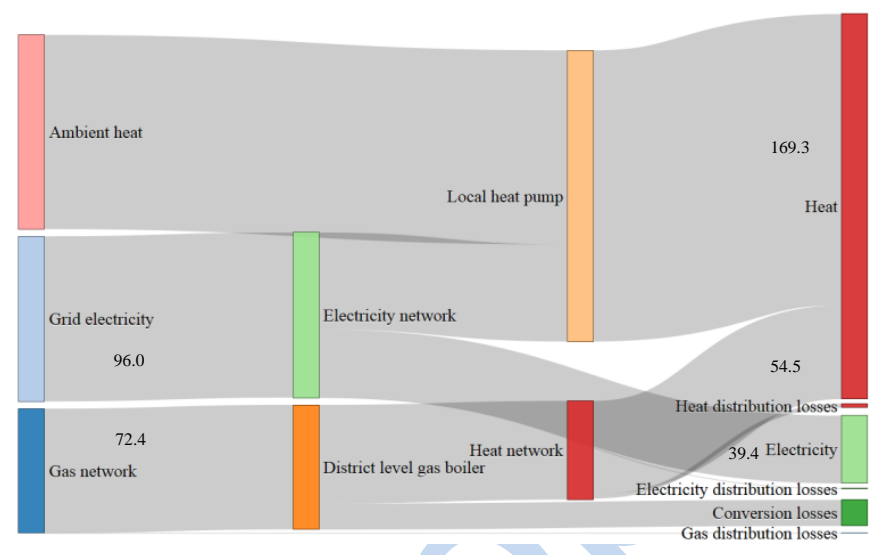

(b) Scenario 2: District level gas boilers + local heat pumps

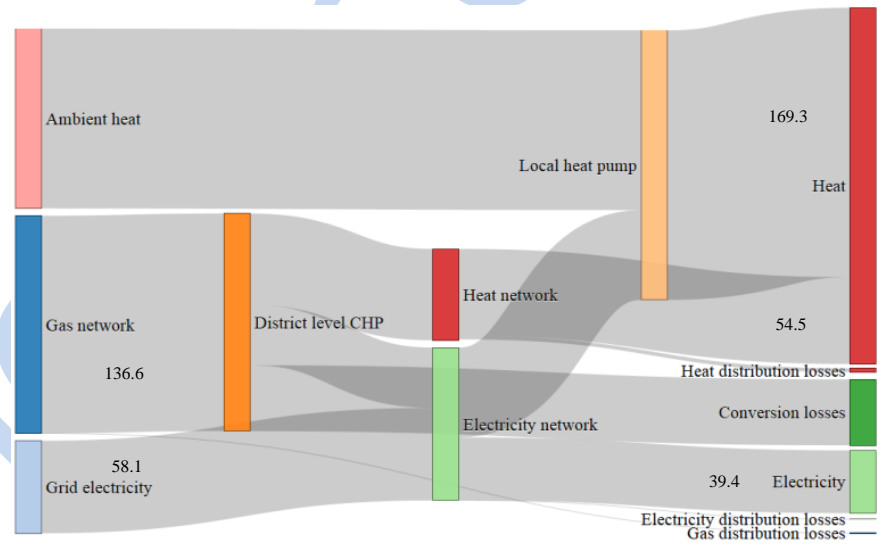

(d) Scenario 4: District level CHP + local heat pumps

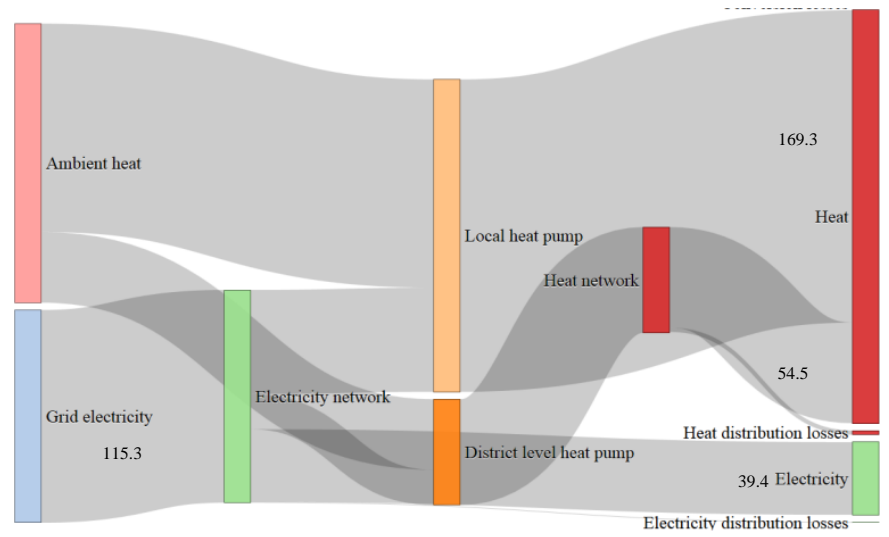

(f) Scenario 6: District level heat pumps + local heat pumps

Figure 18: Flows of energy between electrical, heat and gas networks in total 24 hours for each Scenario 


\subsection{Carbon emissions and energy costs}

Based on the parameters shown in Table 2, two further scenarios with different grid electricity carbon content and grid electricity prices are considered. The resulting $\mathrm{CO}_{2}$ emissions produced from gas fuel consumption and grid electricity for each scenario are shown in Figure 19. Figure 19 (a) shows that, in the case of current grid carbon content, Scenario 5 with all $\mathrm{CHP}$ has lowest $\mathrm{CO}_{2}$ emissions, followed by Scenario 6 with all heat pumps and Scenario 4 with mixed district level CHP and local heat pumps. The largest CO2 emissions exist in original Scenario 1 with all gas boilers. As the carbon content of current grid electricity decreases, Scenario 6 with heat pumps will have lowest $\mathrm{CO}_{2}$ emissions, as shown in (b).

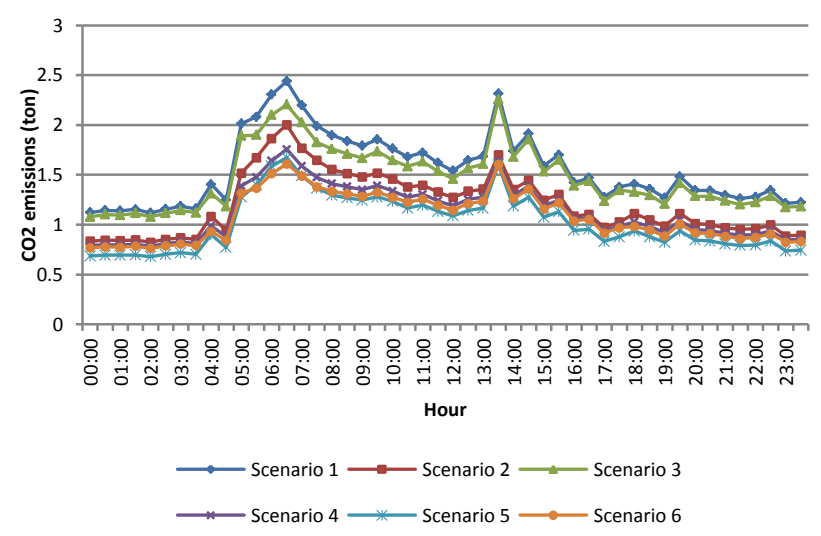

(a) carbon content of grid electricity $0.45 \mathrm{~kg}_{\mathrm{CO} 2} / \mathrm{kWh}$

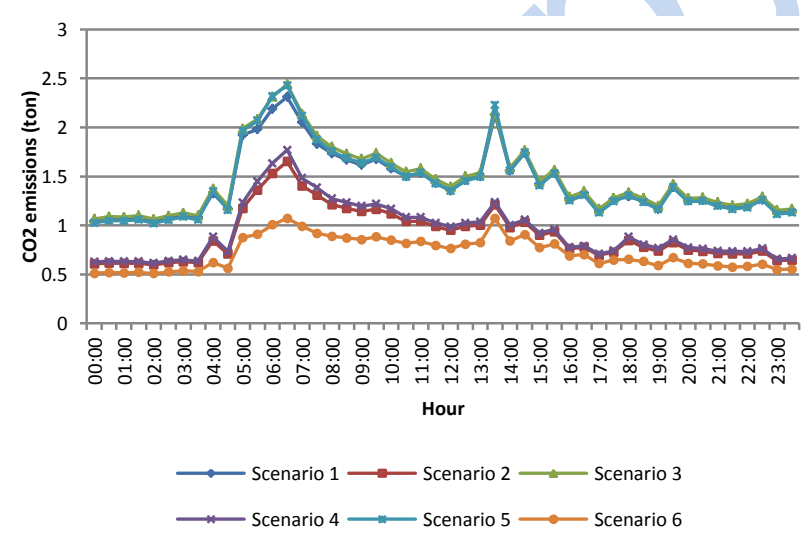

(b) carbon content of grid electricity $0.3 \mathrm{~kg}_{\mathrm{CO} 2} / \mathrm{kWh}$

Figure 19: $\mathrm{CO}_{2}$ emissions in half-hourly time series

The total energy cost from natural gas and grid electricity for each scenario is shown in Figure 20. Figure 20 (a) shows that Scenario 6 with all heat pumps have lower energy cost. The largest energy cost exists in the base Scenario 1 with all gas boilers. As grid electricity price increases and the value placed on exported electricity increases too, the model shows Scenario 5 with CHP will have lower energy cost, as shown in (b).

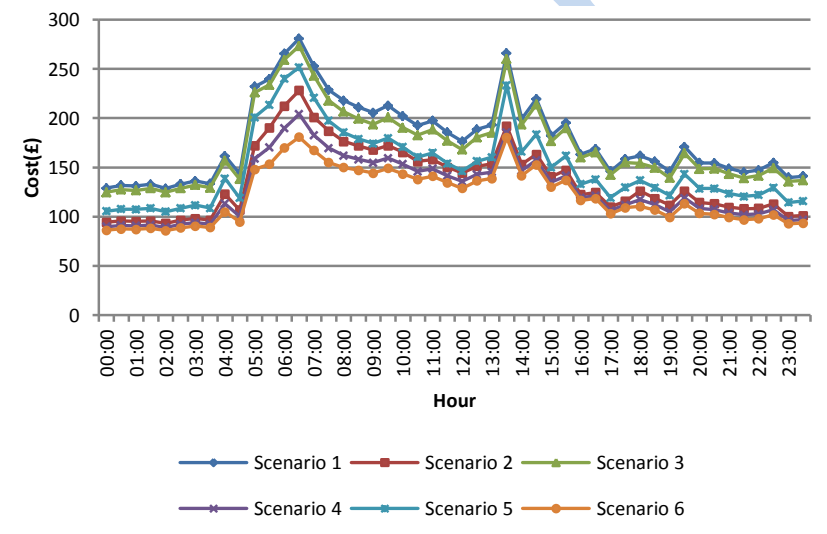

(a) grid electricity price 50.6£/MWh in 2013

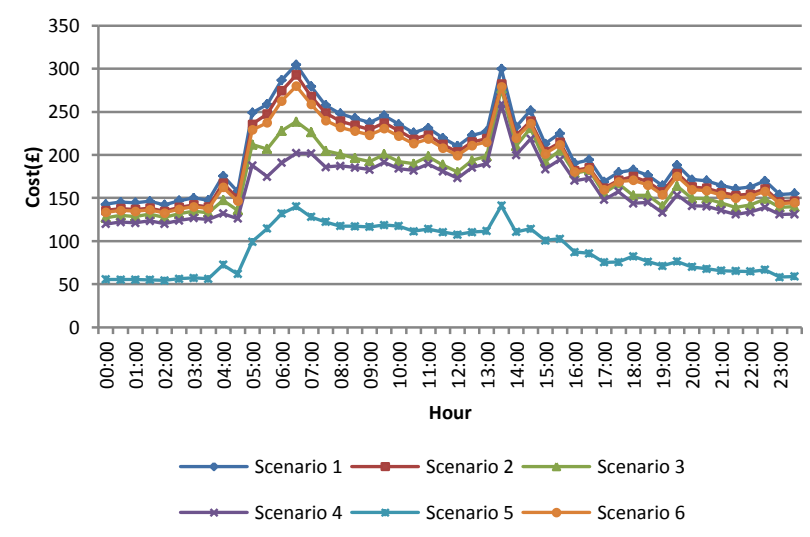

(b) grid electricity price $78.3 £ / \mathrm{MWh}$ in 2030

Figure 20: Energy costs in half-hourly time series 


\section{Conclusions}

An original integrated multi-vector tool specifically developed for district energy system analysis has been introduced in this paper. Such a model can be used for operational assessment of integrated electricity, heat and gas distribution networks with different portfolio of centralised and distributed electricity and heat supply technologies, which can then also inform planning studies. The network linkages have been modelled through a multi-vector efficiency matrix specifically developed to map the transformation of final demands into network energy flows while taking into account the inter-network locations of the individual supply technologies. The relevant coupled electrical, heat and gas flow equations have been solved simultaneously using a NewtonRaphson approach.

The technical impact of different mixes of supply technologies on the three networks has also been analysed in a case study application of a real district at the University of Manchester. The interactions between electricity, heat and gas networks through the conversion components have been clearly demonstrated and quantified. More specifically, different conversion components shift heat and electricity loads across the electricity, heat and gas networks. This then influences the network operation, such as for instance in terms of voltage, temperature and pressure drop and losses. Sankey diagrams of the energy flows across the three networks have also been presented, as a powerful tool to summarise in a visual way the complex multi-energy interactions and losses in the district in different scenarios, from supply to demand through energy conversion technologies. Based on the technical and energy flow data, calculation of carbon emissions and energy costs have also be illustrated.

It has to be pointed out that, being based on the operation of only one day, the energy, emission and economic operational case studies discussed here have been conducted for illustration purposes only, as the focus of the paper is on assessing the multi-vector flows in the three networks. However, although far from and with no ambition of being comprehensive, the illustrative case studies clearly show how changing supply technologies at different levels in the district significantly affects the multi-energy flows in the three networks, and subsequently cash flow and emission balances. In particular, it can be observed how clustering of same technologies such as all CHP or all EHP, even if at different levels, may cause several issues on multiple networks (e.g., high penetration of CHP may cause gas network constraints and high electrical losses, while high penetration of heat pumps might cause to breach electrical network constraints and again high losses). It can also be appreciated that the environmental performance of different technologies will depend on the degree of decarbonisation of the grid (with CHP favoured over heat pumps for high grid carbon content, and the other way round for low grid carbon content), while a full cost benefit analysis would need to be run to address the more complicated economic issue. In any case, it may be suggested that a mixed portfolio of technologies (e.g., a scenario with district level HP and local level heat pumps) might strike the right balance in terms of techno-economic and environmental performance (as for instance discussed in [4]) as well as minimise the impact on local network constraints.

The model can be flexibly adapted to generic network topologies and multi-energy supply technologies, and can therefore be used for practical operational implementations as well as to inform planning of low carbon multienergy systems, by clearly considering network physical requirements (voltage, flow capacity, pressure, etc.) while assessing emission reduction and operational costs. Hence, due to its flexibility and capability, the integrated model presented here has the potential to play an important role in the analysis of a heavily coupled multi-vector energy networks. The model that has been presented has been designed to be user-friendly, and might easily be extended from districts to analysing for instance city-level requirements. In this respect, with the tool that is under development, we aim at supporting informed decisions by city authorities, utility companies and 
energy service companies, as well as the wider community, who may be interested in a holistic multi-energy analysis of the energy sectors and networks.

The work presented here sets the basis for operational analysis of multi-energy systems at a district level, and can then be further deployed as the starting brick to test different control strategies and inform impact assessment as well as planning studies. Other future work includes considering power-to-gas conversion and renewable energy supply at building level, e.g., PV and solar thermal, as well as development of control strategies that can be used for close-to-real-time simulation.

\section{Acknowledgment}

This work was developed with the contribution and within the scope of the FP7 DIMMER project (ref. 609084), which the authors kindly acknowledge. The authors would also like to thank Richard Mizzi, Mark Anderson and Eddie Waldron from ARUP for data support.

\section{References}

[1] P. Mancarella, "MES (multi-energy systems): An overview of concepts and evaluation models," Energy, vol. 65, pp. 1-17, 2014.

[2] X. Liu, J. Wu, N. Jenkins, and A. Bagdanavicius, "Combined analysis of electricity and heat networks," Applied Energy, 2015, http://dx.doi.org/10.1016/j.apenergy.2015.01.102.

[3] M. Geidl and G. Andersson, "Optimal Power Flow of Multiple Energy Carriers," Power Systems, IEEE Transactions on, vol. 22, pp. 145-155, 2007.

[4] T. Capuder and P. Mancarella, "Techno-economic and environmental modelling and optimization of flexible distributed multi-generation options," Energy, vol. 71, pp. 516-533, 2014.

[5] G. Chicco and P. Mancarella, "Distributed multi-generation: A comprehensive view," Renewable and Sustainable Energy Reviews, vol. 13, pp. 535-551, 2009.

[6] P. Mancarella and G. Chicco, "Distributed Multi-Generation: energy models and analyses": Nova Publisher, New York, 2009.

[7] J. Yan, Handbook of Clean Energy Systems, 6 Volume Set: WILEY, 2015.

[8] H. Lund, A. N. Andersen, P. A. Østergaard, B. V. Mathiesen, and D. Connolly, "From electricity smart grids to smart energy systems - A market operation based approach and understanding," Energy, vol. 42, pp. 96-102, 2012.

[9] B. V. Mathiesen, H. Lund, D. Connolly, H. Wenzel, P. A. Østergaard, B. Möller, S. Nielsen, I. Ridjan, P. Karnøe, K. Sperling, and F. K. Hvelplund, "Smart Energy Systems for coherent 100\% renewable energy and transport solutions," Applied Energy, vol. 145, pp. 139-154, 2015 .

[10] R. Lund and B. V. Mathiesen, "Large combined heat and power plants in sustainable energy systems," Applied Energy, vol. 142, pp. 389-395, 2015 .

[11] CHPA, "Integrated Energy: The role of CHP and district heating in our energy future," The Combined Heat and Power Association (CHPA), 2010.

[12] A. Seungwon, L. Qing, and T. W. Gedra, "Natural gas and electricity optimal power flow," Transmission and Distribution Conference and Exposition, IEEE PES, vol. 1, pp. 138-143, 2003.

[13] M. Chaudry, N. Jenkins, and G. Strbac, "Multi-time period combined gas and electricity network optimisation," Electric Power Systems Research, vol. 78, pp. 1265-1279, 2008.

[14] A. Martinez-Mares and C. R. Fuerte-Esquivel, "A Unified Gas and Power Flow Analysis in Natural Gas and Electricity Coupled Networks," Power Systems, IEEE Transactions on, vol. 27, pp. 2156-2166, 2012.

[15] R. Rubio-Barros, D. Ojeda-Esteybar, and A. Vargas, "Energy Carrier Networks: Interactions and Integrated Operational Planning Handbook of Networks in Power Systems II," A. Sorokin, S. Rebennack, P. M. Pardalos, N. A. Iliadis, and M. V. F. Pereira, Eds., ed: Springer Berlin Heidelberg, 2012, pp. 117-167.

[16] M. T. Rees, J. Wu, N. Jenkins, and M. Abeysekera, "Carbon constrained design of energy infrastructure for new build schemes," Applied Energy, vol. 113, pp. 1220-1234, 2014.

[17] B. Awad, M. Chaudry, J. Wu, and N. Jenkins, "Integrated optimal power flow for electric power and heat in a microgrid," Prague, 2009.

[18] D. Connolly, H. Lund, B. V. Mathiesen, and M. Leahy, "A review of computer tools for analysing the integration of renewable energy into various energy systems," Applied Energy, vol. 87, pp. 1059-1082, 2010.

[19] X. Liu, "Combined Analysis of Electricity and Heat Networks," PhD Thesis, Cardiff University, 2013.

[20] P. Mancarella and G. Chicco, "Real-Time Demand Response From Energy Shifting in Distributed Multi-Generation," Smart Grid, IEEE Transactions on, vol. 4, pp. 1928-1938, 2013.

[21] P. Mancarella, "Cogeneration systems with electric heat pumps: Energy-shifting properties and equivalent plant modelling," Energy Conversion and Management, vol. 50, pp. 1991-1999, 2009.

[22] Y. Kikuchi, S. Kimura, Y. Okamoto, and M. Koyama, "A scenario analysis of future energy systems based on an energy flow model represented as functionals of technology options," Applied Energy, vol. 132, pp. 586-601, 2014.

[23] K. Tokimatsu, S. Konishi, K. Ishihara, T. Tezuka, R. Yasuoka, and M. Nishio, "Role of innovative technologies under the global zero emissions scenarios," Applied Energy.

[24] J. M. Cullen and J. M. Allwood, "The efficient use of energy: Tracing the global flow of energy from fuel to service," Energy Policy, vol. 38, pp. 75-81, 2010.

[25] K. Soundararajan, H. K. Ho, and B. Su, "Sankey diagram framework for energy and exergy flows," Applied Energy, vol. 136, pp. 1035-1042, 2014. 
B. M. Weedy, B. J. Cory, N. Jenkins, J. B. Ekanayake, and G. Strbac, Electric power systems 5th ed.: Wiley, 2012.

J. J. Grainger and W. D. Stevenson, Power system analysis: McGraw-Hill (New York), 1994.

G. Kusic, "Bus Reference Frame," in Computer-Aided Power Systems Analysis, Second Edition, ed: CRC Press, 2008, pp. 141-191.

K. C. B. Steer, A. Wirth, and S. K. Halgamuge, "Control period selection for improved operating performance in district heating networks," Energy and Buildings, vol. 43, pp. 605-613, 2011.

Siemens, "PSS Sincal 7.0 heating Manual," 2010.

H. Zhao, "Analysis, modelling and operational optimization of district heating systems," PhD Thesis, Technical University of Denmark, 1995. B. Bøhm, S. Ha, W. Kim, B. Kim, T. Koljonen, H. Larsen, M. Lucht, Y. Park, K. Sipila, and M. Wigbels, Simple models for operational optimisation: Department of Mechanical Engineering, Technical University of Denmark, 2002.

J. M. Coulson, J. F. Richardson, and R. K. Sinnott, "Coulson \& Richardson's Chemical Engineering. Volume 1: Fluid Flow, Heat Transfer \& Mass Transfer," Butterworth-Heinemann Ltd, p. 501, 1999.

A. Osiadacz, Simulation and analysis of gas networks: Gulf Pub. Co., 1987.

National Grid, "Gas Ten Year Statement," 2014.

S. Ingram, S. Probert, and K. Jackson, "The Impact of Small Scale Embedded Generation Upon The Operating Parameters of Distribution Networks," DTi New and Renewable Energy Program, K/EL/00303/04/01, 2003.

Coherent Research Ltd. Available: https://www.ems.estates.manchester.ac.uk/DCS/Logon.aspx?ReturnUrl=\%2fDCS [accessed: 18.09.2014] National Grid, "2014 Future Energy Scenarios," 2014.

F. Li, "Spatially explicit
College London, 2013.

Pöyry. ( 2010). Options for Low-Carbon Power Sector Flexibility to 2050: A report to the Committee on Climate Change, Oxford, UK. Available: http://www.theccc.org.uk/reports/fourth-carbon-budget/supporting-research

EPA, Catalog of CHP Technologies: U.S. Environmental Protection Agency (EPA) Combined Heat and Power Partnership, 2008.

Central networks. (2006). Network design manual. Available: <http://www.eon-uk.com/downloads/network_design_manual.pdf >. [accessed on 14.09.14]. 